Portland State University

PDXScholar

\title{
The Effects of Scale Variation on Single-Family Residential Water Use in Portland, OR
}

Matthew Ryan Lee Bonnette

Portland State University

Follow this and additional works at: https://pdxscholar.library.pdx.edu/open_access_etds

Part of the Water Resource Management Commons

Let us know how access to this document benefits you.

\section{Recommended Citation}

Bonnette, Matthew Ryan Lee, "The Effects of Scale Variation on Single-Family Residential Water Use in Portland, OR" (2017). Dissertations and Theses. Paper 3505.

https://doi.org/10.15760/etd.5389

This Thesis is brought to you for free and open access. It has been accepted for inclusion in Dissertations and Theses by an authorized administrator of PDXScholar. Please contact us if we can make this document more accessible: pdxscholar@pdx.edu. 
The Effects of Scale Variation on Single-Family Residential Water Use in Portland, OR

by

Matthew Ryan Lee Bonnette

A thesis submitted in partial fulfillment of the requirements for the degree of

Master of Science

in Geography

Thesis Committee:

Heejun Chang, Chair

Geoffrey Duh

Barbara Brower

Portland State University

2017 
Abstract

With growing urban populations and increasing concerns over the effects of climate change on water supplies, there has recently been a significant amount of interdisciplinary research focused on identifying the drivers of urban water use. Due to unavailability of individual or household level data, these studies are often limited to using spatially aggregated data. There is concern that this aggregation of data may be leading to misrepresentations of the drivers of urban water use, yet there have been few studies that have addressed this concern. As in all spatial quantitative analyses, studies in this area should consider how the spatial scales chosen for analysis are affecting the results. The purpose of this research is to use a case study of single-family residential (SFR) water use in Portland, Oregon to determine the extent to which scale variation significantly affects the patterns of SFR water use, and whether household scale water use is influenced by neighborhood and census tract characteristics. The results of this analysis provide evidence that aggregating household scale water use data can mask meaningful patterns in SFR water use and potentially provide misleading information on what is influencing water use habits. This research also shows that using the chosen exploratory variables, there is a statistically significant, but not substantial, cross-scale influence on household scale water use by neighborhood and census tract characteristics. 
Acknowledgements

I would like to thank Dr. Heejun Chang for his support and guidance throughout the development and execution of this project. I would also like to thank my thesis committee members Dr. Geoffrey Duh and Dr. Barbara Brower for their comments on my thesis. Thanks also goes to Christopher Grant for conducting the extensive processing required to convert the raw household water use data into a format that is suitable for analysis. Finally, I would like to thank Hossein Parandvash at the Portland Water Bureau for providing the original water billing data used in this study. 
Table of Contents

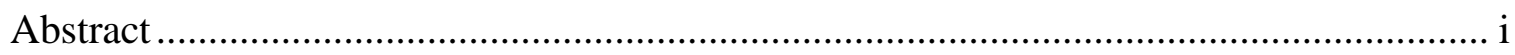

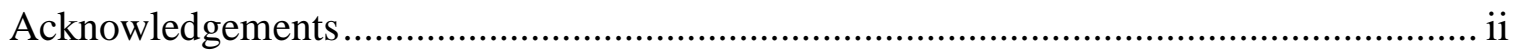

List of Tables ..................................................................................................... iv

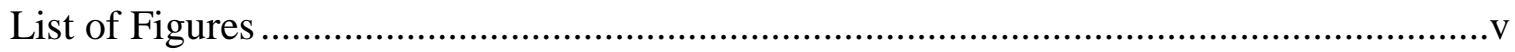

Chapter 1

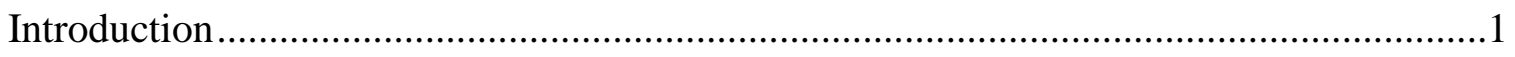

Chapter 2

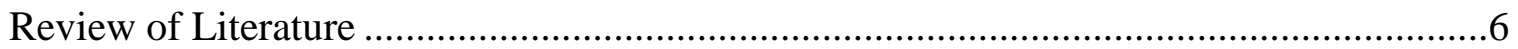

Chapter 3

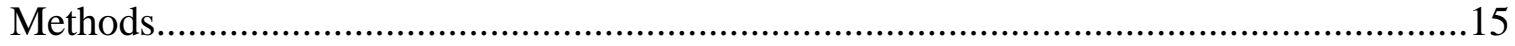

Chapter 4

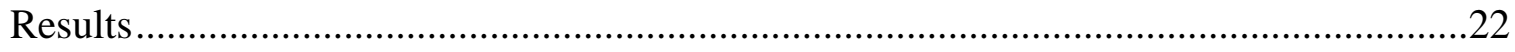

Chapter 5

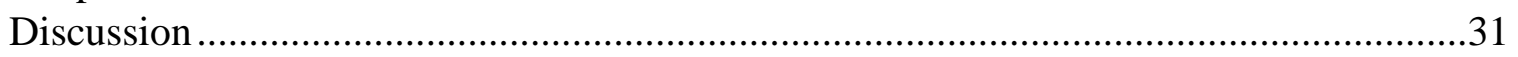

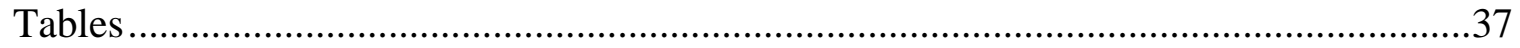

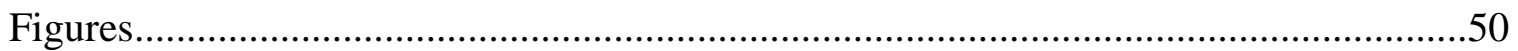

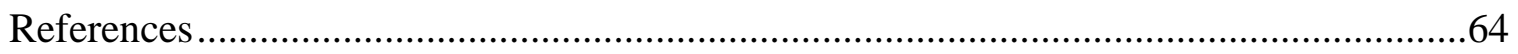

Appendix: Process for Transforming Billing Data to Monthly Water Use .....................71 
List of Tables

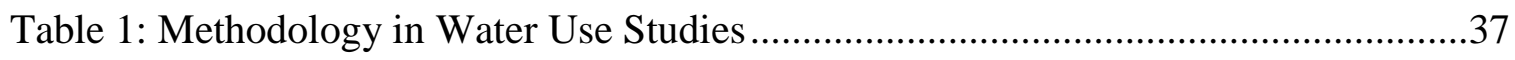

Table 2: Significant Explanatory Variables in Water Use Studies ................................39

Table 3: Spatial Scales in Water Use Studies ...............................................................41

Table 4: Descriptive statistics of the dependent and independent variables for the SFRs used in this study

Table 5: Spatial error regression for SFR monthly water use at the household scale

Table 6: Spatial error regression for SFR monthly water use at the census block scale

Table 7: Spatial error regression for SFR monthly water use at the census block group scale

Table 8: Spatial error regression for SFR monthly water use at the census tract scale .46

Table 9: Spatial error regression for SFR monthly water use at the neighborhood scale

Table 10: Multi-level regression for SFR summer monthly water use at the household scale using census tract and census tract plus household variables

Table 11: Multi-level regression for SFR summer monthly water use at the household scale using neighborhood and neighborhood plus household variables 
List of Figures

Figure 1: This map shows the location of Portland within the state of Oregon, while the inset map provides a closer view of the Portland city limits as well as a general understanding of land use through aerial photography

Figure 2: This chart provides a simplified view of how the household water use and exploratory variables were aggregated to the census block, census block group, census tract, and neighborhood scales.

Figure 3: The below figure displays 2011 mean monthly SFR water use at the a) census block, b) census block group, c) census tract, and d) neighborhood scales for Portland, Oregon.

Figure 4: The below figure displays 2011 mean summer monthly SFR water use at the a) census block, b) census block group, c) census tract, and d) neighborhood scales for Portland, Oregon.

Figure 5: The below figure displays 2011 mean winter monthly SFR water use at the a) census block, b) census block group, c) census tract, and d) neighborhood scales for Portland, Oregon.

Figure 6: The multi-level regression models used in this study showing how household, neighborhood, and census tract characteristics influence household level water use in Portland, Oregon.

Figure 7: Local Moran's I clusters for a) annual, b) summer, and c) winter SFR water use at the census block scale

Figure 8: Getis-Ord Gi* hot spots for a) annual, b) summer, and c) winter SFR water use at the census block scale

Figure 9: Local Moran's I clusters for a) annual, b) summer, and c) winter SFR water use at the census block group scale

Figure 10: Getis-Ord Gi* hot spots for a) annual, b) summer, and c) winter SFR water use at the census block group scale

Figure 11: Local Moran's I clusters for a) annual, b) summer, and c) winter SFR water use at the census tract scale

Figure 12: Getis-Ord $\mathrm{Gi}^{*}$ hot spots for a) annual, b) summer, and c) winter SFR water use at the census tract scale

Figure 13: Local Moran's I clusters for a) annual, b) summer, and c) winter SFR water use at the neighborhood scale

Figure 14: Getis-Ord Gi* hot spots for a) annual, b) summer, and c) winter SFR water use at the neighborhood scale 
Introduction

The 21 st century is the first time in recorded history that more than $50 \%$ of the Earth's human population is living within urban areas (United Nations Population Fund 2007). While the population of urban areas continues to rise, water providers struggle to meet the increasing water needs of their residents (Grafton et al. 2011). According to the Intergovernmental Panel on Climate Change (IPCC), climate change is likely to further reduce water supplies in many areas of the world, exacerbating the struggles of water providers trying to meet growing demands (IPCC 2014). The water-related impacts of climate change will vary by location, forcing water managers to consider many factors outside of simple water provision (Chang and Bonnette 2016).

In Australia, the Millennium Drought greatly impacted ecosystems, water supplies, and the economy (Dijk et al. 2013). In South Korea, based on climate change projections, average drought intensity is expected to increase (Nam et al. 2015). In central Europe, the forests of southern Slovakia and Hungary are likely to experience substantial drying in the future (Hlásny et al. 2014). In the United States, the headlines are filled with stories of drought and water shortages in many arid southwestern cities (Johnson 2016, Boxall 2017); however, many cities throughout the eastern, central, and northwestern portions of the country are also facing these challenges due to growing demand, water pollution, and groundwater depletion (Hornberger et al. 2015). In the Pacific Northwest region of the United States, it was determined that while per capita water use is decreasing, population growth is inhibiting decreases in overall water use in the Puget Sound Region (Polebitski et al. 2011) and the Portland Metropolitan area (Parandvash 
and Chang 2016). The residents of Flint, Michigan continue to face the catastrophic levels of lead and bacteria in their water supply that have been in the news since 2014 (Butler et al. 2016). In the central United States, the Ogallala Aquifer, an essential water source for much of the country's agricultural production, is being depleted by six inches to several feet per year (Wheeler-Cook et al. 2008).

In response to these issues, the IPCC has called on the academic community to focus research on the impacts that climate change has on water demand and on strategies that will contribute to the improvement of water management systems (Bates et al. 2008). This has led to the publication of a significant amount of research focusing on residential water consumption (House-Peters and Chang 2011).

Using a variety of methods, many of these studies claim to provide water managers with information that will allow them to implement policies aimed at increasing water conservation and decreasing water demand in areas under their purview. Halper et al. (2015) provided water managers with a study that would allow them to consider using public green spaces and swimming pools as a way to mitigate outdoor household water use. Lee (2016) analyzed the influence Low-Income Rate Assistance Programs (LIRA) have on levels of water demand in five California cities. Baerenklau et al. (2014) showed water providers that switching from a uniform rate price structure to an increasing block rate structure is an effective tool for reducing household water demand in the Eastern Municipal Water District of southern California, while resulting in only relatively small end-user price increases. Brelsford and Abbott (2017) provided indirect evidence that responses to drought, improved wastewater policies, and other policy measures play a significant role in reducing water demand. Rathnayaka et al. (2014) 
identified factors that influence water use variability, aiming to provide the tools for water managers to adopt Integrated Urban Water Management techniques. While these studies, and many others like them, aim to assist water providers in reducing household water demand, there is one important factor that is rarely considered - spatial scale.

In studies on any physical or social processes, scale should be an integral part when considering methodological approaches (Ruddell and Wentz 2009). There have been very few urban water use studies that have analyzed water use spatially rather than temporally, and even fewer have considered the effects that variation in spatial scales of dependent and independent variables can have on the results. Ouyang et al. (2014) conducted a multi-scale analysis of urban water use in Phoenix, Arizona. The goal of the study was to determine if this multi-scale analysis would reveal the presence of common geographic analysis problems like the ecological fallacy problem, the modifiable areal unit problem (MAUP), and the uncertain geographic context problem (UGCoP) in water consumption research (Dark and Bram 2007, Kwan 2012, Ouyang et al. 2014). While the authors found no evidence of these problems, they admitted that there were several obstacles that impeded them from truly addressing these issues in their study. The main limitation, and the main reason that most urban water use studies do not include multiscale analysis, is that it is difficult to obtain household water use data to the same geographic extent as data that are aggregated to other scales, with surveys being the primary source of household or individual water use habits (Ouyang et al. 2014). Hong and Chang (2014) observed similar limitations in their multi-level study of the influence of sociodemographic and behavioral characteristics on household water consumption patterns in the Portland metropolitan area. In order to fully understand the impacts of 
scale variation and the effects of cross-scale interactions in urban water use studies, it is necessary to have access to household level water use data for the entire study area.

\section{Research Questions}

This thesis aims to evaluate the effects that scale variation can have on the spatial patterns of single-family residential (SFR) water use and its common explanatory variables, as well as to determine if there are significant influences on household scale water use by neighborhood and census tract characteristics. Understanding these crossscale interactions provides policymakers and water managers with detailed insight into the methods and areas that should be targeted to reduce water use.

This analysis seeks to answer the following research questions:

1) Using the same set of explanatory variables, is there significant variation in the influence of the chosen variables on SFR water use as the datasets are aggregated to higher levels?

2) Using the same set of explanatory variables, do the predictors of SFR water use vary by season?

3) Do neighborhood and census tract characteristics have a significant influence on the amount of household scale water use?

\section{Structure of Document}

The remainder of this thesis is structured as follows. Chapter 2 provides a review of relevant literature on urban water use studies, with a focus on those primarily concerned with spatial analysis rather than temporal analysis, as well as potential 
problems these studies can face by not considering spatial scale. Chapter 3 then provides a description of the study area, the data used, and methodology undertaken. Chapter 4 describes the results found through this analysis. Finally, Chapter 5 provides a discussion of how these results inform the given research questions, recommendations to water providers and policymakers, and ways to continue improving this type of research going forward. 
Review of Literature

Studies of urban residential water use have been conducted in many locations around the world, using a variety of quantitative and qualitative data and analysis methods. With advances in technology and data processing, modeling and analysis methods continue to improve and evolve, allowing for more variables attributed to water consumption to be incorporated into urban water use studies (House-Peters and Chang 2011). The studies predominantly take a quantitative approach to data analysis, yet there is an inherent humanistic aspect, as well. Many forms of statistical analysis and modeling have been used in recent literature to assess and identify the factors that influence urban water use (Table 1). Spatial error regression models, like the ones used in this study, have been shown to be an effective tool for analyzing residential water use (Chang et al. 2010). A large variety of socioeconomic, property characteristic, climatic, and behavioral variables have been analyzed to assess their influence on urban water use (Table 2). The eight explanatory variables used for this study (Maximum Temperature, Precipitation, Home Size, Lot Size, Home Age, Property Value, and Deciduous/Coniferous Tree Cover) have been shown throughout the literature to significantly influence residential water use. Some of the common scales used in residential water use research are the census block, census block group, census tract, and city levels (Table 3). The three census delineations and an additional neighborhood scale are used in this study to determine variations between household scale SFR water use and these aggregated scales. The remainder of this chapter will further explore the common methods, variables, and scales used throughout this branch of research, as well as potential problems that can arise. 
Analysis Methods in Residential Water Use Studies

The majority of residential water use studies took a temporal approach to their analysis, either using some form of regression model to complete their analysis or focusing on the effectiveness of non-regression based analysis methods. These studies using non-regression models are quite varied and often specifically aimed to introduce new methods like cluster analysis (Cardell-Oliver 2013), genetic programming (Liu et al. 2014), and factor analysis (Panagopoulos 2014) into this field of study.

While these various temporal analyses provide vital information on the drivers of urban water consumption, they are not as well suited at providing water managers and policymakers with specific areas in which to target water conservation efforts. However, several recent studies have shown the advantages of using a spatial approach to understanding this issue, pointing out that population and economic growth cannot explain consumption levels alone, but also need biophysical and socioeconomic factors with a typically spatial dependence (de Maria André and Carvalho 2014). Additionally, water consumption and conservation have been shown to have a cascading effect meaning the behavior of one household has an influence on its neighbors and vice versa (Janmaat 2013). Using a spatial approach to study water consumption will likely provide a clearer explanation of the factors influencing variations in household water use (de Maria André and Carvalho 2014).

Among those studies that have focused primarily on spatial analysis, there is not a consensus on which type of statistical model provides the highest level of predictability. Breyer et al. (2012) used a spatial lag regression model, while de Maria André and Carvalho (2014) used both a spatial autoregressive model and a spatial autoregressive 
moving average model. Janmaat (2013) took an additional step, using all three of these model types in the analysis. In addition to these, other recent studies have used a variety of models, including: a spatial error regression model to account for spatial influences on the residuals (Chang et al. 2010), a spatial heteroscedasticity and autocorrelation consistent (HAC) model to account for the influence of proximity to amenities that influence water use (Halper et al. 2015), and a spatial linear mixed-effects model to measure cross-scale influences (Ouyang et al. 2014). While all of these models have their advantages, the spatial linear mixed-effects model used by Ouyang et al. (2014) is the only one that addresses the impacts that spatial scale and cross-scale influences can have on the results of urban water use studies.

\section{Explanatory Variables in Residential Water Use Studies}

The most commonly used variables in recent literature have been water price, income, household size, population, temperature, precipitation, and the presence of various water efficiency devices in the home. The wide variety of independent variables used in studies of urban water consumption will likely continue to expand in order to examine the effectiveness of new policies and programs that are implemented in an attempt to promote water conservation.

While there are many variables that have been used in these studies, very few of them are useful for completing a cross-scale analysis including household scale water use. This deficiency is related to the availability of these variables at the household scale. Many of the variables commonly used are only available at the census block group scale or higher in order to protect the privacy of residents (Ouyang et al. 2014). In order to 
complete a cross-scale analysis, only those variables available at the household scale, such as maximum temperature, precipitation, property value, home age, home size, lot size, and deciduous/coniferous tree cover, were used in this study.

Maximum temperature has been consistently shown to have a significant impact on end-user water consumption, justifying its use in this study. A study by Sebri (2013) found that a $10 \%$ quarterly increase to maximum temperature would lead to more than a 9\% increase in quarterly household water use in Tunisia. Adamowski et al. (2012) found that daily maximum temperature is the primary driver of daily summer demand in Montreal, Quebec. Mini et al. (2014) found in Los Angeles, California that an increase of one degree Celsius in the maximum temperature leads to an increase of $2.9 \%$ in monthly SFR water use at the census tract scale.

Precipitation is one of the most common explanatory variables used in residential water use studies, and thus is included in this study. Ashoori et al. (2016) found that precipitation was the only variable in their model of SFR water use in Los Angeles that had a significant impact, with a one centimeter increase in annual precipitation leading to a decrease of residential water demand of 629,000 cubic meters. Price et al. (2014) determined that household water demand in Albuquerque, New Mexico is negatively correlated with precipitation. Grafton et al. (2011) found that precipitation had a statistically significant negative relationship with household water consumption datasets from ten different countries.

This study used property value as a proxy for household income, since income data is not available at the household scale. Janmaat et al. (2013) set precedent for this when they found that, in four different models, property value was shown to have a 
significant positive relationship with household water consumption in Kelowna, British Columbia, similar to the relationship typically shown between income and water use in other studies of water use in the Portland metropolitan area (Chang et al. 2010, HousePeters et al. 2010).

Age of home was used for this study as it has been shown in the literature to influence water consumption, with older homes using more water and newer homes using less, likely due to updated building and appliance standards. Harlan et al. (2009) found that year built has a significant negative relationship with household water consumption in Phoenix, Arizona, showing that older homes use more water. Ouyang et al. (2014) also found evidence of this relationship in Phoenix, Arizona, showing that home age had a significant positive relationship with SFR water use in the Phoenix metropolitan area at the census tract and city scales, but there was not a significant relationship at the household scale. Janmaat et al. (2013) noted that home age was shown to have a significant positive relationship with household water consumption in Kelowna, British Columbia across all four of their models.

Home size has been shown to influence household water use, particularly in regard to indoor water use. Chang et al. (2010) found that home size has a significant positive relationship with SFR water use in Portland, Oregon. Harlan et al. (2009) also showed that home size has a significant positive relationship with household water consumption in Phoenix, Arizona. Janmaat et al. (2013) again verified this relationship, showing that home size has a significant positive relationship with residential water use in Kelowna, British Columbia. 
Lot size has also been shown throughout the literature to have a significant positive relationship with water use, primarily impacting outdoor water use. Renwick and Green (2000) found that lot size has a positive significant relationship with residential water use in a study of eight California water agencies. Harlan et al. (2009) found that lot size has a significant positive relationship with household water consumption in Phoenix, Arizona. Janmaat et al. (2013) also showed that lot size has a significant positive relationship with residential water use in Kelowna, British Columbia.

Many studies throughout the literature have found that landscape characteristics such as impervious surface area, vegetative cover, and garden space can have an influence on residential water use. A study by Gage and Cooper (2015) showed that variations in canopy height significantly influenced outdoor water use in Aurora, Colorado. Thus, this study used a dataset of coniferous and deciduous tree cover in order to capture these effects.

\section{Spatial Scales in Residential Water Use Studies}

While researchers focused on water use are often interested in the water use habits of SFRs, this individual household data is often not available for these analyses. Even if researchers are provided household scale data, they are often required to aggregate the data to a coarser spatial scale in order to coincide with the scale of their explanatory variables or to meet confidentiality restrictions (Ouyang et al. 2014). There has been little research into how this spatial aggregation may be affecting the results of these studies. Without insight into the issues that can be caused by this spatial aggregation and scale variation, researchers may be leading water providers and policymakers to implement 
ineffective or misguided water policies. This study provides a cross-scale comparison of water use at the household, census block, census block group, census tract, and neighborhood scales in order to determine if the common scales in this field of study are masking or misrepresenting information that could be beneficial to water managers and policymakers.

\section{Scale Problems in Geographic Research}

Due to unavailability of household scale data, urban water use studies are typically limited to using aggregated water use data (Ouyang et al. 2014). As with many areas of study, there is concern that rescaling the data used could lead to a loss of continuity of the analysis (Easterling and Polsky 2004). There are very few studies in this area that address how scale variation can alter the patterns of water use and its drivers, and even fewer address the common scale problems that regularly arise in geographic studies - ecological fallacy, MAUP, and UGCoP (Ouyang et al. 2014). It is important for researchers in this area, as with all spatial analysis, to understand that the scale of observation is integral to understanding spatial phenomena and processes (National Research Council 1997).

As with most geographic or spatial analyses, water use studies use areal units that come in a variety of shapes and sizes, which can lead to complications in the statistical analysis. These complications arise from the differently sized and/or shaped areal units leading to different results, and are what is commonly referred to as the modifiable areal unit problem (MAUP). The MAUP can be broken down into two related issues: 1) there are differences in results related to the number of units that a given area is broken into - 
differences caused by disaggregation, and 2) there are differences in results related to the way in which smaller units are combined into larger ones for analysis - differences caused by aggregation (Dark and Bram 2007). Studies of water use are likely affected by both the aggregation and disaggregation of data. Water use data and household characteristics are often aggregated, while socioeconomic and demographic variables can be either aggregated or disaggregated depending on the data available for a given study area. This use of aggregated data, typically at census designated areal units, is somewhat concerning as this process has been shown to lead to unreliable results in many geographic multivariate studies (Fotheringham and Wong 1990).

The ecological fallacy problem is another scale related issue in quantitative analysis that has close ties to the MAUP. Ecological fallacy occurs when the results of a study based on aggregated data are applied to specific individuals or sites within the analyzed unit (Openshaw 1984). This problem often occurs because studies that use aggregated data do not always distinguish between the results from analysis of the aggregated data sets and the real-world processes that influence the individual data used in the aggregation (Dark and Bram 2007). With the prominence of data aggregation in water use studies, the ecological fallacy problem should be a consideration for any research looking into this area when attempting to explain household level water use patterns based on spatially aggregated data.

The UGCoP is a geographic problem that is related to errors or misinterpretations of phenomena that result from how areal units in spatial analysis are delineated and the amount that these delineations deviate from the area that is truly relevant in a geographic context. The UGCoP arises because it is very difficult to determine the size and shape of 
areal units that are geographically relevant to a given phenomena (Kwan 2012). With urban water use studies typically using established areal units (census levels, city limits, etc.) instead of units derived from water use patterns, it is likely that this problem exists in this area of research. Additionally, previous studies have shown spatial dependence in SFR water use, but they have not directly addressed UGCoP (Ouyang et al. 2014).

There are additional concerns that even when some household scale data are used in these water use studies, they still do not successfully capture the spatial heterogeneity of household level water use and the characteristics of the study area that drive them. This is primarily attributed to household data only being available through means of survey, resulting in only a small portion of the population being analyzed (Ouyang et al. 2014). Having access to a full set of household scale water use data allows for a better investigation of how the heterogeneity of the data relates to other landscape characteristics in the study area. 
Methods

\section{Study Area}

This case study will focus on Portland, Oregon (Figure 1). The average temperature in Portland is $12.45^{\circ} \mathrm{C}$, and the average precipitation is $914 \mathrm{~mm}$, using 1981 to 2010 normals (US Climate Data 2017). While the Pacific Northwestern United States is typically identified as having a humid climate, it is actually an ideal area for water consumption studies as summers are dry and there is a strong reliance on surface water supplies that are also likely to be greatly impacted by climate change (Breyer et al. 2012, Polebitski et al. 2011). With $80 \%$ of rainfall typically occurring between October and March, summer droughts are a growing concern in this region (Chang et al. 2014).

There are several distinct regions of the city to consider while assessing SFR water use across the city. The western portion of the city is known as the West Hills, and is one of the most affluent areas in the city, leading to an expectation of higher water use. Between the West Hills area and the Willamette River to the east is the Downtown area of the city, which is a typical urban environment with fewer and smaller SFRs. The northern and inner southeast portions of the city are former industrial and low-income areas that have experienced significant gentrification recently, and continue to grow. Finally, the eastern portion of the city is a more suburban environment, with an abundance of SFRs.

As of 2010, Portland is home to almost 620,000 people living in 265,000 housing units - of which over 60\% are SFRs (US Census Bureau 2010). The primary water provider for the residents of Portland, and the rest of the metropolitan area, is the 
Portland Water Bureau, which provides drinking water to over 950,000 residents pulled primarily from surface water within the Bull Run Watershed located east of downtown Portland (Portland Water Bureau 2016). Being the water provider to such a large area allows the Portland Water Bureau to monitor household scale water use over a large spatial extent.

Data

For this project, monthly SFR water use data for the year 2011 was chosen as the dependent variable. This year was chosen due to temperature and precipitation being near average, and the availability of other characteristic data for this time period. The Portland Water Bureau (PWB) collects a combination of quarterly and monthly metered water use data from their customers, which does not allow for easy analysis, as the metering intervals are not the same for every household with customers having the option to choose between 1-month and 3-month billing intervals (Appendix). The PWB provided records for 152,596 SFRs at the household scale in this format, meaning additional processing, performed by Dr. Chris Grant, was required before analysis. The data in its raw format was first converted into daily household water use values for each day in the 2011 study period by assigning each day in a given monthly or quarterly interval an equal portion of the whole value. Theses daily values were then aggregated into monthly household water use for each calendar month. After this additional processing was completed, any entries that did not have continuous data available for the study period were removed, leaving records for 142,844 SFRs. The data was then converted from the centum cubic feet $(\mathrm{CCF})$ to kiloliters $(\mathrm{kL})$, and average monthly values were calculated 
for the annual period, summer period (June, July, and August), and the winter or base period (December, January, and February). Finally, these three water use variables were $\log$ transformed in order to normalize the data for analysis.

Both temperature and precipitation have commonly been shown to be drivers of residential water consumption in many areas of the world (Liu et al. 2014, Price et al. 2014, Romano et al. 2014). For this study, monthly maximum temperature $\left({ }^{\circ} \mathrm{C}\right)$ and monthly precipitation data $(\mathrm{mm})$ - raster datasets at a scale of 30 by 30 arcseconds - were acquired from the PRISM Climate Group at Oregon State University for 2011. Each household in the final water use data set was spatially joined to these climate datasets, and average monthly maximum temperature and average monthly precipitation were calculated for the annual, summer, and winter time periods.

A study by Chang et al. (2010) determined that property characteristics, such as tax-assessed value, prove to be acceptable substitutes for the socioeconomic variables commonly used in water use studies. For this study, datasets that provide property value, year built, home size, and lot size at the household level were acquired from the Oregon METRO's Regional Land Information System (RLIS) and joined to each household record (Oregon METRO RLIS 2011). The property value was converted to $\$ 100 \mathrm{~K}$, year built was converted to a new variable (age) by subtracting year built from the study year (2011), and home size and lot size were converted into metric units - square meters and hectares, respectively.

A study by Gage and Cooper (2015) showed that variations in tree canopy can have an influence on end user water consumption. For this study, a dataset including deciduous and coniferous tree cover for the Portland metropolitan area was acquired from 
the City of Portland (City of Portland 2016). This data was spatially joined to each household record to determine the percentage of each lot covered by deciduous and coniferous trees.

Once all eight explanatory variables were incorporated into the household records, any record with incomplete data for any of the chosen variables was removed, leaving 138,518 household records. The descriptive statistics for these variables can be found in Table 4. These records were then aggregated (Figure 2) to the census block scale (Minnesota Population Center 2011), after which, any block with less than five households was removed from the dataset along with any households they contain. This resulted in a final total of 134,666 household records and 8,289 census blocks in the analysis. The final data processing step was aggregating the household data to census block group, census tract, and neighborhood scales (Minnesota Population Center 2011, Bureau of Planning and Sustainability 2014). This resulted in 419 census block groups, 142 census tracts, and 111 neighborhoods being used in the analysis. The census delineated features were chosen for this analysis because they are the spatial scales that are typically used in residential water use studies, while the neighborhood features were chosen to determine if a different type of areal unit delineation could be more geographically relevant in residential water use studies.

Water Use Patterns at Varying Spatial Scales

The 2011 annual, summer, and winter mean monthly SFR water use were mapped at the household, census block, census block group, census tract, and neighborhood scales for a visual pattern analysis (Figures 3 - 5). Using the Spatial Statistics Toolbox in 
ESRI's ArcGIS 10.4 software, global Moran's I, local Moran's I, and local Getis-Ord G tests were run to determine patterns of spatial autocorrelation in the data. The global Moran's I index was found by using the Spatial Autocorrelation (Moran's I) tool, which determines whether the chosen variable displays a dispersed, random, or clustered spatial pattern across the chosen study area. The local Moran's I was analyzed with the Cluster and Outlier Analysis (Anselin Local Moran’s I) tool, which calculates the Moran’s I for each feature in a dataset and produces an output of clusters and outliers. High-high clusters identify high value features surrounded by other high value features, and low-low clusters identify low value features surrounded by other low value features. The high-low outliers identify high value features in areas expected to have low values, and low-high outliers identify low value features in areas expected to have high values. The local Getis-Ord G test was run using the Hot Spot Analysis (Getis-Ord Gi*) tool, which identifies features that are statistically significant hot and cold spots, and produces an output of these areas. The hot spots represent areas of high values, and the cold spots represent areas of low values. Using these spatial pattern tools with SFR water use can be beneficial to water managers and policymakers, allowing them to create spatially targeted educational campaigns and other policies to reduce water consumption in high use areas.

\section{Influence of Explanatory Variables on Water Use at Varying Spatial Scales}

It has been previously shown in water use studies, including in Portland, Oregon, that spatial error models are effective at mitigating overestimates of the influence of explanatory variables on water use (Chang et al. 2010). A spatial error regression model was used for this analysis as it accounts for any spatial autocorrelation among residuals 
resulting from the dependent and independent variables. A spatial error model was run using GeoDa v1.8.14 software for annual, summer, and winter water use at the five chosen scales using a Queen contiguity weight matrix. Each model was run using the appropriate maximum temperature and precipitation as the independent variables, as well as the other six chosen variables - property value, home age, home size, lot size, percentage of deciduous tree cover, and percentage of coniferous tree cover.

\section{Cross-scale Influences on Household Water Use}

The final portion of this research was to determine cross-scale interactions with household scale water use, specifically looking at how census tract and neighborhood characteristics influence individual SFR water use (Figure 6). These scales were primarily chosen because they cover similar sized areas while not sharing similar borders. In order to accomplish this, four multi-level regression models were developed using GeoDa v1.8.14 software. These multi-level models allow for the incorporation of values for each of the common explanatory variables at nested scales into the analysis of what is determining household scale water use. The first model explores the influence of SFR summer water use at the census tract scale and the other chosen census tract characteristics on household scale SFR water use. The second model explores household scale SFR water use using the same census tract variables as the first model, with the addition of household scale characteristics. The third model explores the influence of SFR summer water use at the neighborhood scale and the other chosen neighborhood characteristics on household scale SFR water use. The fourth model explores household 
scale SFR water use using the same neighborhood variables as the third model, with the addition of household scale characteristics. 
Results

\section{Water Use Patterns at Varying Spatial Scales}

At the household scale, the Global Moran's I test showed statistically significant clustering in the annual, summer, and winter water use data sets. Annual water use has a Moran's index of 0.053 , summer water use has an index of 0.041 , and winter water use has an index of 0.023 . This can be further seen in the Local Moran's I maps of annual, summer, and winter water use, with high-high clusters primarily located in the western portion of the city and low-low clusters located primarily on the east side of the Willamette River. The Getis-Ord Gi* maps show the majority of hot spots in the western and far eastern portions of the city, and the majority of cold spots are in the near east side and northern portion of the city.

At the census block scale, the Global Moran's I test showed statistically significant clustering in the annual, summer, and winter water use data sets. Annual water use has a Moran's index of 0.136 , summer water use has an index of 0.117 , and winter water use has an index of 0.069 . This can be further seen in the Local Moran's I maps of annual, summer, and winter water use (Figure 7), with high-high clusters primarily located in the western and far eastern portions of the city and low-low clusters located primarily close in on the east side of the Willamette River. The Getis-Ord Gi* maps show a similar pattern with the majority of hot spots in the western and far eastern portions of the city, and the majority of cold spots are in the near east side and northern portion of the city (Figure 8). 
At the census block group scale, the Global Moran's I test showed statistically significant clustering in the annual, summer, and winter water use data sets. Annual water use has a Moran's index of 0.105 , summer water use has an index of 0.079 , and winter water use has an index of 0.139 . The Local Moran's I maps at this scale varied by season, unlike the previously discussed scales (Figure 9). Annual and winter water use show high-high clusters primarily located in the western and far southeastern portions of the city and low-low clusters located primarily close in on the east side of the Willamette River, while summer water use shows high-high clusters in the western and northeastern portions of the city and low-low cluster primarily close in on the east side. The Getis-Ord Gi* maps show a similar pattern (Figure 10). Annual and winter use hot spots are primarily in the western and far eastern portions of the city, and the majority of cold spots are in the near east side and northern portion of the city, while summer use shows hot spots in the west and northeast with cold spots on the near east side. These differences could be attributed to larger lot sizes in the western portions leading to higher summer water use (Hong and Chang 2014), with larger household sizes in the southeast leading to higher winter and annual water use (House-Peters et al. 2010).

At the census tract scale, the Global Moran's I test showed statistically significant clustering in the annual, summer, and winter water use data sets. Annual water use has a Moran's index of 0.121 , summer water use has an index of 0.083 , and winter water use has an index of 0.147 . The Local Moran's I maps at this scale varied by season, similar to the census block group scale (Figure 11). Annual use shows high-high clusters primarily located in the western and far southeastern portions of the city and low-low clusters located primarily close in on the east side of the Willamette River. Summer water use 
shows high-high clusters in the western portion of the city and low-low clusters primarily close in on the east side, while winter use shows high-high clusters in the far eastern portion of the city and low-low clusters primarily close in on the east side. The Getis-Ord Gi* maps show a similar pattern (Figure 12). Annual use hot spots are primarily in the western and far southeastern portions of the city, and the majority of cold spots are in the near east side and northern portion of the city. Summer use shows hot spots in the west with cold spots on the near east side, while winter use shows hot spots in the far eastern portions of the city and cold spots in areas just east and west of the Willamette River and northern portions of the city.

At the neighborhood scale, the Global Moran's I test showed statistically significant clustering in the annual, summer, and winter water use data sets. Annual water use has a Moran's index of 0.338 , summer water use has an index of 0.224 , and winter water use has an index of 0.304 . The Local Moran's I maps at this scale varied by season, but not in the same way as the census block group and census tract scales (Figure 13). Annual and summer water use show high-high clusters primarily located in the western portion of the city and low-low clusters located primarily close in on the east side of the Willamette River, while winter water use shows high-high clusters in the western and far southeastern portions of the city and low-low clusters primarily close in on the east side. The Getis-Ord Gi* maps show a similar pattern (Figure 14). Annual and summer use hot spots are primarily in the western portion of the city, and the majority of cold spots are in the near east side and northern portion of the city, while winter use shows hot spots in the west and southeast with cold spots on the near east side. 
Influence of Explanatory Variables on Water Use at Varying Spatial Scales

The spatial error regression models of monthly SFR water use at the household scale resulted in $\mathrm{R}^{2}$ values of $0.138,0.152$, and 0.070 for annual, summer, and winter water use, respectively (Table 5). In the annual water use model, the significant explanatory variables are Maximum Temperature (+), Precipitation (+), House Age (-), Lot Area (+), House Area (+), Coniferous Cover (-), Deciduous Cover (-), and Lambda (+) - the autoregressive coefficient. The significant explanatory variables for the summer water use model are: Precipitation (-), Property Value (-), House Age (-), Lot Area (+), House Area (+), Coniferous Cover (-), Deciduous Cover (-), and Lambda (+). Finally, the significant explanatory variables for the winter water use model are: Maximum Temperature (-), Property Value (-), House Age (-), Lot Area (+), House Area (+), and Lambda (+). House Age, Lot Area, House Area, and Lambda were the only variables found to be significant and the same sign across all three seasons. Several variables did not have the expected relationship based on previous studies, specifically: Precipitation showed a positive relationship with annual use, Maximum Temperature showed a negative relationship with winter water use, and Property Value showed a negative relationship with summer and winter water use. Further inspection of outlier values, additional socioeconomic and behavioral variables, and water pricing structures could provide more insight into these unexpected results.

The spatial error regression models of monthly SFR water use at the census block scale resulted in $\mathrm{R}^{2}$ values of $0.469,0.528$, and 0.229 for annual, summer, and winter water use, respectively (Table 6). In the annual water use model, the significant explanatory variables are: Precipitation (+), Property Value (-), House Age (-), Lot 
Area (+), House Area (+), Coniferous Cover (+), Deciduous Cover (-), and Lambda (+).

The significant explanatory variables for the summer water use model are:

Precipitation (-), Property Value (+), House Age (-), Lot Area (+), House Area (+), Coniferous Cover (+), Deciduous Cover (-), and Lambda (+). Finally, the significant explanatory variables for the winter water use model are: Maximum Temperature (-), Property Value (-), House Age (-), Lot Area (+), House Area (+), and Lambda (+). House Age, Lot Area, House Area, and Lambda were the only variables found to be significant and the same sign across all three seasons. Several variables did not have the expected relationship, specifically: Precipitation showed a positive relationship with annual use, Maximum Temperature showed a negative relationship with winter water use, Property Value showed a negative relationship with annual and winter water use, and Coniferous Tree Cover showed a positive relationship with annual and summer water use.

The spatial error regression models of monthly SFR water use at the census block group scale resulted in $\mathrm{R}^{2}$ values of $0.857,0.845$, and 0.646 for annual, summer, and winter water use, respectively (Table 7). In the annual water use model, the significant explanatory variables are: Maximum Temperature (+), Property Value (-), Lot Area (+), House Area (+), Coniferous Cover (+), Deciduous Cover (+), and Lambda (+). The significant explanatory variables for the summer water use model are: Precipitation (-), House Age (-), Lot Area (+), House Area (+), Coniferous Cover (+), and Lambda (+). Finally, the significant explanatory variables for the winter water use model are: Property Value (-), Lot Area (+), House Area (+), Coniferous Cover (+), Deciduous Cover (+), and Lambda (+). Lot Area, House Area, Coniferous Tree Cover, and Lambda were the only variables found to be significant and the same sign across all three seasons. Several 
variables did not have the expected relationship, specifically: Property Value showed a negative relationship with annual and winter water use, Coniferous Tree Cover showed a positive relationship with water use in all three seasons, and Deciduous Tree Cover showed a positive relationship with annual and winter water use.

The spatial error regression models of monthly SFR water use at the census tract scale resulted in $\mathrm{R}^{2}$ values of $0.896,0.855$, and 0.790 for annual, summer, and winter water use, respectively (Table 8). In the annual water use model, the significant explanatory variables are: Maximum Temperature (+), Property Value (-), Lot Area (+), House Area (+), Deciduous Cover (+), and Lambda (+). The significant explanatory variables for the summer water use model are: Precipitation (-), Property Value (-), House Area (+), Coniferous Cover (+), and Lambda (+). Finally, the significant explanatory variables for the winter water use model are: Property Value (-), Lot Area (+), House Area (+), Deciduous Cover (+), and Lambda (+). House Area, Property Value, and Lambda were the only variables found to be significant and the same sign across all three seasons. Several variables did not have the expected relationship, specifically: Property Value showed a negative relationship with water use in all three seasons, Coniferous Tree Cover showed a positive relationship with summer use, and Deciduous Tree cover showed a positive relationship with annual and winter water use.

The spatial error regression models of monthly SFR water use at the neighborhood scale resulted in $\mathrm{R}^{2}$ values of $0.818,0.806$, and 0.634 for annual, summer, and winter water use, respectively (Table 9). In the annual water use model, the significant explanatory variables are: Property Value (-), Lot Area (+), House Area (+), and Deciduous Cover (-). The significant explanatory variables for the summer water use 
model are: Precipitation (-), Property Value (-), Lot Area (+), House Area (+), and Lambda (+). Finally, the significant explanatory variables for the winter water use model are: Maximum Temperature (-), Property Value (-), House Age (-), House Area (+), and Coniferous Cover (+). House Area and Property Value were the only variables found to be significant and the same sign across all three seasons. Several variables did not have the expected relationship, specifically: Maximum Temperature showed a negative relationship with winter water use, Property Value showed a negative relationship with water use in all three seasons, and Coniferous Tree Cover showed a positive relationship with winter water use.

\section{Cross-scale Influences on Household Water Use}

Four multi-level regression models were used to examine the cross-scale relationships between household scale summer monthly SFR water use and the characteristics of the census tracts and neighborhoods in which they are located. The first and second models focused on the interactions between the household and census tract scales (Table 10). The first model used census tract SFR summer monthly water use and the census tract scale of the eight explanatory variables used throughout this study to explore cross-scale influences on household water use. This model had an Adjusted $\mathrm{R}^{2}$ value of 0.067, with CT Summer Water Use (+), CT Summer Max Temperature (+), CT Property Value (-), CT Lot Area (-), CT Home Area (+), CT Coniferous Cover (+), and CT Deciduous Cover (-) shown to be significant at least at the 0.1 level. Several variables did not have the expected relationship, specifically: Census Tract Property Value showed 
a negative relationship, Census Tract Lot Area showed a negative relationship, and Census Tract Coniferous Tree Cover showed a positive relationship.

The second model used the same census tract variables as the first, but added the eight explanatory variables at the household scale. This model had an Adjusted $\mathrm{R}^{2}$ value of 0.165, with Summer Precipitation (-), Property Value (-), Lot Area (+), House Area (+), Coniferous Cover (-), Deciduous Cover (-), CT Summer Water Use (+), CT Summer Precipitation (+), CT Property Value (-), CT House Age (+), CT Lot Area (-), CT Coniferous Cover (+), and CT Deciduous Cover (-) shown to be significant at least at the 0.1 level. Several variables did not have the expected relationship, specifically: Household Property Value showed a negative relationship, Census Tract Summer Precipitation showed a positive relationship, Census Tract Property Value showed a negative relationship, Census Tract Lot Area showed a negative relationship, and Census Tract Coniferous Tree Cover showed a positive relationship.

The third and fourth models focused on the interaction between the household and neighborhood scales (Table 11). The third model used neighborhood SFR summer monthly water use and the neighborhood scale of the eight explanatory variables used throughout this study to explore cross-scale influences on household water use. This model had an Adjusted R² value of 0.074, with Neighborhood Summer Use (+), Neighborhood Summer Max Temperature (-), Neighborhood Property Value (-), Neighborhood Lot Area (-), Neighborhood Home Area (+), and Neighborhood Coniferous Cover (-) shown to be significant at least at the 0.1 level. Several variables did not have the expected relationship, specifically: Neighborhood Summer Maximum 
Temperature showed a negative relationship, Neighborhood Property Value showed a negative relationship, and Neighborhood Lot Area showed a negative relationship.

The fourth model used the same neighborhood variables as the third, but added the eight explanatory variables at the household scale. This model had an Adjusted $\mathrm{R}^{2}$ value of 0.169, with Summer Max Temperature (+), Summer Precipitation (-), Property Value (-), Lot Area (+), Home Area (+), Coniferous Cover (-), Deciduous Cover (-), Neighborhood Summer Water Use (+), Neighborhood Summer Max Temperature (-), Neighborhood Summer Precipitation (+), Neighborhood Property Value (-), Neighborhood Lot Area (-), and Neighborhood Home Area (-) shown to be significant at least at the 0.1 level. Several variables did not have the expected relationship, specifically: Household Property Value showing a negative relationship, Neighborhood Summer Maximum Temperature showing a negative relationship, Neighborhood Summer Precipitation showing a positive relationship, Neighborhood Property Value showing a negative relationship, Neighborhood Lot Area showing a negative relationship, and Neighborhood Home Area showing a negative relationship. 
Discussion

\section{Water Use Patterns at Varying Spatial Scales}

The spatial autocorrelation tests show minor clustering of household scale water use for the annual, summer, and winter datasets. The main clustering is of high values in the West Hills area of Portland, which is a more affluent part of the city, making this pattern not surprising. The census block scale shows moderate clustering with more high values located in the West Hills, as well. High values are also prevalent in the eastern portion of the city, which could potentially be attributed to the higher proportion of Hispanic and Asian populations, in which it is more culturally common to have multiple generations of families living in a single residence, thus leading to larger household sizes and more water use. Finally, there are several high use areas in the near eastside and northern portions of the city, which could be influenced by recent influxes in income as gentrification continues to take place.

In the aggregate scales of census block group, census tract, and neighborhood, the cluster patterns become much stronger and more visually evident. This variation in clustering intensity between the household scale and the aggregate scales suggests that individual households' water use behaviors may not be influenced as strongly by their immediate neighbors as the aggregated scales suggest. These aggregate scales that are often used in water use studies are masking the more nuanced patterns and distributions of high and low SFR water users, and could be strongly influenced by outlier households. If water managers and policymakers use these aggregated scales to implement policies 
that are spatially targeted at high water use areas, a significant number of average and low water users could be adversely impacted.

Influence of Explanatory Variables on Water Use at Varying Spatial Scales

The $\mathrm{R}^{2}$ values for all three household scale models were drastically lower than those from any of the other scales. Maximum temperature was significant in both the annual and winter models, with the annual model showing the positive relationship often seen in similar studies and the winter model showing a negative relationship (Chang et al. 2014). This negative relationship could potentially be related to variations in household size across the city, and including this variable in further studies would be beneficial. Precipitation was significant in both the annual and summer models, with the annual model showing an unanticipated positive relationship (Chang et al. 2014). This positive relationship could potentially be attributed to residents staying indoors during Portland's wet winters and springs, leading to an increase in indoor water use. Property value had a significant negative relationship in the summer and winter models; however, the coefficients are so small, the variable has a limited effect in this study (Janmaat 2013). House age shows an unexpected significant negative relationship in all three models, but again the coefficient is very small, showing a minimal effect on water use (Halper et al. 2015). This negative relationship could be attributed to the older homes typically being smaller, on smaller lots, and many having been remodeled with more efficient devices. Both lot area and house area have significant positive relationships in all three models, which is expected as larger homes tend to lead to higher indoor water use and larger lots tend to lead to higher outdoor water use (Chang et al. 2010, Hong and Chang 2014). Both 
coniferous and deciduous cover show significant negative relationships in the annual and summer models. This relationship is expected as more tree cover leads to less sunlight and lower ambient temperatures. Finally, Lambda - the autoregressive coefficient - shows a significant positive relationship in all three models. This suggests that there is a spatial influence on household level water use. However, with very low $\mathrm{R}^{2}$ values and many low coefficient values, these models suggest that this set of explanatory variables may not be appropriate for explaining SFR water use in Portland. Using a number of socioeconomic (income, education, age, etc.) and behavioral (water conservation perceptions, political views, water efficiency device use, etc.) variables in this analysis could provide better insight into the influences of household scale SFR water use, as well as why some of the signs of coefficients change across scales and seasons. However, these types of variables are difficult to obtain at the household scale, limiting their usefulness in an analysis of spatial scale variation.

The $\mathrm{R}^{2}$ values at the census block, census block group, and census tract scales for annual, summer, and winter use models were substantially higher than those of the household scale. Additionally, the majority of the significant coefficients in these models have substantially larger absolute values than their counterparts in the household scale models. The three models at the neighborhood scale also show significantly stronger $\mathrm{R}^{2}$ values and stronger significant coefficients than the household scale; however, the Lambda variable is only significant for the summer use model. This indicates that, at the neighborhood scale, it is likely that there is only a spatial dependence in regards to outdoor water use. The drastic differences between the spatial error regression models for the aggregate scales and those of the household scale suggest that the aggregate scale 
models are providing one answer, but they are missing significant influences on actual household scale SFR water demand.

\section{Cross-scale Influences on Household Water Use}

Four multi-level regression models were created to assess cross-scale influences on SFR summer water use. The first two models were aimed at analyzing the influence of census tract characteristics on household scale summer water use. The first model showed that the census tract characteristics alone have a statistically significant, but not substantial, impact on household scale summer water use. The adjusted $\mathrm{R}^{2}$ value was approaching zero, and while seven variables were shown to be statistically significant, their coefficient values were very low. The second model incorporated both the census tract characteristics and household characteristics. This model showed slightly better results, with an improved adjusted $\mathrm{R}^{2}$ value. However, the significant coefficient values were still low, and several of the relationship signs for variables contradicted the sign of the same variable at the other scale.

The third and fourth models were aimed at assessing the influence of neighborhood characteristics on household scale summer water use. While the adjusted $\mathrm{R}^{2}$ values of these models were slightly higher than their census tract counterparts, they were also unable to show a substantial cross-scale influence, suffering from similarly poor model results. The results of these four models could indicate that household water use is not strongly impacted by cross-scale influences; however, it is also possible that these cross-scale influences could be identified using a different set of explanatory variables. 


\section{Conclusion}

Studies on urban water use are an important tool for understanding and predicting changes in water demand. Water managers and policymakers could greatly benefit from these types of studies as they deal with increasing demands due to population growth and diminishing supply related to climate change. As researchers continue to study these challenges, it is important to remember that this is an inherently spatial issue. Given this, the spatial scale in which these analyses are done must be given serious consideration. Misleading results and advice could be detrimental to water providers and the people they serve.

The purpose of this study was to answer three specific questions, aimed at providing water managers and policymakers comprehensive insight into how spatial scale variation can influence SFR water use studies in Portland, Oregon and beyond. The first was to determine if there is significant variation in the influence of the chosen variables on household level water use as the datasets were aggregated to higher levels. It was discovered that aggregating water use data can mask some of the more intricate patterns in household level water use. It was also found that the variables that substantially explain water use patterns at aggregated scales are not necessarily the same as those that explain them at the household level. Seeing the differences in the patterns between spatial scales will allow water managers and policymakers to have a better understanding of the patterns of high and low SFR water use in their region, enabling them to make more educated assessments of where to target educational campaigns and policies aimed at reducing residential water consumption. 
The second question was to determine if the predictors of SFR household water use vary over seasons. It was discovered that, at each spatial scale, the determinants of water use varied across season. It was also found that these seasonal variations differed across the spatial scales. Identifying these seasonal variations will allow water managers and policymakers to better understand where to target educational campaigns and policies focused on reducing outdoor water use (high summer water users) and indoor water use (high winter water users).

The final question was to determine if neighborhood and census tract characteristics have a significant influence on the amount of household water use. It was discovered that the potential for cross-scale and spatial influences on household water use exists, but the variables used in this study did not have a strong impact. Further studies of these cross-scale influences on household scale could assist water managers and policymakers in identifying how effective policies and education campaigns targeted at high use neighborhood or census tracts are at influencing household scale SFR water use. Future research should continue to explore the effects of spatial aggregation in these studies, the different variables that may influence water use habits (Straus et al. 2016), and cross-scale and spatial influences on water use. 
Table 1: Methodology in Water Use Studies

\begin{tabular}{|c|c|}
\hline Analysis Method & Examples from the Literature \\
\hline Agent-based Model & Yuan et al. 2014 \\
\hline Artificial Neural Networks & Adamowski et al. 2012 \\
\hline $\begin{array}{l}\text { Autoregressive Integrated } \\
\text { Moving Average }\end{array}$ & $\begin{array}{l}\text { Praskievicz and Chang 2009; } \\
\text { Adamowski et al. 2012; Chang et al. } 2014\end{array}$ \\
\hline Cluster Analysis & Cardell-Oliver 2013 \\
\hline Cobb-Douglas Model & Dharmaratna and Harris 2012 \\
\hline Cointegration Model & Zaied and Binet 2015 \\
\hline $\begin{array}{l}\text { Coupled Wavelet and Artificial } \\
\text { Neural Networks }\end{array}$ & Adamowski et al. 2012 \\
\hline Double-log Regression Model & Liu et al. 2015 \\
\hline $\begin{array}{l}\text { Dynamic Error Correction } \\
\text { Model }\end{array}$ & Fullerton et al. 2013 \\
\hline Econometric Model & $\begin{array}{c}\text { Renwick and Green 2000; } \\
\text { Woltemade and Fuellhart 2013 }\end{array}$ \\
\hline Factor Analysis & Panagopoulos 2014; Yu et al. 2015 \\
\hline Fixed-effects Panel Regression & Price et al. 2014 \\
\hline Genetic Programming & Liu et al. 2015 \\
\hline Integrated Assessment Model & Hejazi et al. 2014 \\
\hline Latent Class Model & Pérez-Uridiales et al. 2014 \\
\hline $\begin{array}{l}\text { Linear Latent Growth Curve } \\
\text { Model }\end{array}$ & Jorgensen et al. 2013 \\
\hline Linear Mixed-effects Model & Ouyang et al. 2014; Romano et al. 2014 \\
\hline Linear Regression & $\begin{array}{l}\text { Adamowski et al. 2012; } \\
\text { Woltemade and Fuellhart 2013; Yu et al. 2015; } \\
\text { Ashoori et al. } 2016\end{array}$ \\
\hline Log-linear Regression & Rinaudo et al. 2012; Baerenklau et al. 2014 \\
\hline
\end{tabular}




\begin{tabular}{|c|c|}
\hline Multinomial Logit Model & Reynaud 2013 \\
\hline Multiregression Model & Shandas and Parandvash 2010 \\
\hline Natural Log-linear Regression & Grafton et al. 2011; Mini et al. 2014 \\
\hline Nonlinear Regression Model & Adamowski et al. 2012; Yasar et al. 2012 \\
\hline $\begin{array}{l}\text { Ordinary Least Squares } \\
\text { Regression Model }\end{array}$ & $\begin{array}{l}\text { Praskievicz and Chang 2009; Chang et al. 2010; } \\
\text { House-Peters et al. 2010; Breyer et al. 2012; } \\
\text { Browne et al. 2013; Janmaat 2013; Sebri 2013; } \\
\text { Chang et al. 2014; Rathnayaka et al. } 2014\end{array}$ \\
\hline Piecewise Linear Regression & Chang et al. 2010 \\
\hline Random Forest Analysis & Gage and Cooper 2015 \\
\hline Sequential Regression Model & Fielding et al. 2012 \\
\hline Spatial Autoregressive Model & Janmaat 2013; de Maria Andre and Carvalho 2014 \\
\hline $\begin{array}{c}\text { Spatial Autoregressive Moving } \\
\text { Average Model }\end{array}$ & Janmaat 2013; de Maria Andre and Carvalho 2014 \\
\hline Spatial Error Model & $\begin{array}{l}\text { Chang et al. 2010; Janmaat 2013; } \\
\text { de Maria Andre and Carvalho } 2014\end{array}$ \\
\hline Spatial HAC Method & Halper et al. 2015 \\
\hline $\begin{array}{l}\text { Spatially Disaggregate Water } \\
\text { Demand Model }\end{array}$ & Polebitski et al. 2011 \\
\hline Stepwise Linear Regression & Chang et al. 2014 \\
\hline Stone-Geary Functional Form & Dharmaratna and Harris 2012 \\
\hline Two-stage Least Squares Model & Polycarpou and Zachariadis 2013 \\
\hline Wavelet Analysis & Adamowski et al. 2012 \\
\hline
\end{tabular}


Table 2: Significant Explanatory Variables in Water Use Studies

\begin{tabular}{|c|c|}
\hline $\begin{array}{l}\text { Significant Explanatory } \\
\text { Variables (Relationship } \\
\text { to water use) }\end{array}$ & Examples from the Literature \\
\hline \multicolumn{2}{|r|}{ Climate Variables } \\
\hline Daylight Length (-) & Praskievicz and Chang 2009 \\
\hline Precipitation $(+)$ & Polycarpou and Zachariadis 2013 \\
\hline Precipitation (-) & $\begin{array}{c}\text { Grafton et al. 2011; Dharmaratna and Harris 2012; } \\
\text { Ozan and Alsharif 2013; Chang et al. 2014; Liu et al. 2014; } \\
\text { Ouyang et al. 2014; Price et al. 2014; Romano et al. 2014; } \\
\text { Zaied and Binet } 2015\end{array}$ \\
\hline Temperature (+) & $\begin{array}{l}\text { Renwick and Green 2000; Praskievicz and Chang 2009; } \\
\text { Grafton et al. 2011; Dharmaratna and Harris 2012; } \\
\text { Rinaudo et al. 2012; Yasar et al. 2012; } \\
\text { Polycarpou and Zachariadis 2013; Reynaud 2013; } \\
\text { Sebri 2013; Chang et al. 2014; Ouyang et al. 2014; } \\
\text { Price et al. } 2014\end{array}$ \\
\hline Wind Speed (-) & Praskievicz and Chang 2009 \\
\hline \multicolumn{2}{|r|}{ Socioeconomic Variables } \\
\hline Education $(+)$ & House-Peters et al. 2010; Baerenklau et al. 2014 \\
\hline Household Size (+) & $\begin{array}{l}\text { House-Peters et al. 2010; Dharmaratna and Harris 2012; } \\
\text { Fielding et al. 2012; Jorgensen et al. 2013; Sebri 2013; } \\
\text { Baerenklau et al. 2014; Ouyang et al. 2014; } \\
\text { Rathnayaka et al. 2014; Pérez-Uridiales et al. } 2016\end{array}$ \\
\hline Income $(+)$ & $\begin{array}{c}\text { Grafton et al. 2011; Polebitski et al. 2011; } \\
\text { Dharmaratna and Harris 2012; Fielding et al. 2012; } \\
\text { Rinaudo et al. 2012; Jorgensen et al. 2013; } \\
\text { Polycarpou and Zachariadis 2013; Willis et al. 2013; } \\
\text { Baerenklau et al. 2014; } \\
\text { de Maria André and Carvalho 2014; Ouyang et al. 2014; } \\
\text { Romano et al. 2014; Yuan et al. } 2014\end{array}$ \\
\hline Income (-) & $\begin{array}{l}\text { Renwick and Green 2000; Dharmaratna and Harris 2012; } \\
\text { Reynaud } 2013\end{array}$ \\
\hline
\end{tabular}




\begin{tabular}{|c|c|}
\hline \multicolumn{2}{|c|}{ Property Characteristic Variables } \\
\hline Bathrooms (+) & Janmaat 2013; de Maria Andre and Carvalho 2014 \\
\hline Home Age (+) & Janmaat 2013; Ouyang et al. 2014; Halper et al. 2015 \\
\hline Home Age (-) & Reynaud 2013 \\
\hline Home Size (+) & $\begin{array}{c}\text { Chang et al. 2010; Grafton et al. 2011; } \\
\text { Polebitski et al. 2011; Janmaat 2013 }\end{array}$ \\
\hline Lot Size (+) & $\begin{array}{c}\text { Renwick and Green 2000; House-Peters et al. 2010; } \\
\text { Polebitski et al. 2011; Janmaat 2013; Willis et al. 2013; } \\
\text { Hong and Chang 2014; Ouyang et al. 2014; } \\
\text { Halper et al. 2015 }\end{array}$ \\
\hline Property Value (+) & Janmaat 2013 \\
\hline Rooms (+) & Grafton et al. 2011 \\
\hline Swimming Pool (+) & Fielding et al. 2012; Janmaat 2013; Rathnayaka et al. 2014 \\
\hline Tree Cover (Unspecified) & Gage and Cooper 2015 \\
\hline
\end{tabular}


Table 3: Spatial Scales in Water Use Studies

\begin{tabular}{|c|c|}
\hline Analysis Scale & Examples from the Literature \\
\hline Household & $\begin{array}{l}\text { Grafton et al. 2011; Fielding et al. 2012; } \\
\text { Cardell-Oliver 2013; Janmaat 2013; } \\
\text { de Maria André and Carvalho 2014; } \\
\text { Jorgensen et al. 2014; Ouyang et al. 2014; } \\
\text { Pérez-Urdiales et al. 2014; Price et al. 2014; } \\
\text { Rathnayaka et al. 2014; Gage and Cooper 2015 }\end{array}$ \\
\hline Census Block & House-Peters et al. 2010 \\
\hline Census Block Group & $\begin{array}{c}\text { Chang et al. 2010; Shandas and Parandvash 2010; } \\
\text { Breyer et al. 2012; Gage and Cooper } 2015\end{array}$ \\
\hline Census Tract & $\begin{array}{l}\text { Polebitski et al. 2011; Baerenklau et al. 2014; } \\
\text { Mini et al. 2014; Ouyang et al. } 2014\end{array}$ \\
\hline City & $\begin{array}{l}\text { Praskievicz and Chang 2009; Adamowski et al. 2012; } \\
\text { Rinaudo et al. 2012; Yasar et al. 2012; } \\
\text { Polycarpou and Zachariadis 2013; Reynaud 2013; } \\
\text { Woltemade and Fuellhart 2013; Chang et al. 2014; } \\
\text { Ouyang et al. 2014; Panagopoulos 2014; } \\
\text { Romano et al. 2014; Yuan 2014; Liu et al. 2015; } \\
\text { Ashoori et al. 2016 }\end{array}$ \\
\hline Regional & $\begin{array}{c}\text { Renwick and Green 2000; } \\
\text { Dharmaratna and Harris 2012; Sebri 2013; } \\
\text { Haque et al. 2015; Yu et al. } 2015\end{array}$ \\
\hline Country & Zaied and Binet 2015 \\
\hline Global & Hejazi et al. 2014 \\
\hline
\end{tabular}


Table 4: Descriptive statistics of the dependent and independent variables for the SFRs used in this study $(n=134,666)$

\begin{tabular}{|c|c|c|c|c|}
\hline & Mean & Std. Dev. & Min & $\operatorname{Max}$ \\
\hline Annual Monthly Use (kL) & 16.562 & 11.742 & 0.880 & $1,850.684$ \\
\hline Summer Monthly Use (kL) & 20.352 & 23.900 & 0.747 & $6,424.812$ \\
\hline Winter Monthly Use (kL) & 13.807 & 9.407 & 0.636 & 825.418 \\
\hline $\begin{array}{l}\text { Annual Monthly } \\
\text { Max Temperature (C) }\end{array}$ & 15.701 & 0.073 & 15.318 & 15.941 \\
\hline $\begin{array}{l}\text { Summer Monthly } \\
\text { Max Temperature (C) }\end{array}$ & 23.842 & 0.097 & 23.431 & 24.158 \\
\hline $\begin{array}{l}\text { Winter Monthly } \\
\text { Max Temperature (C) }\end{array}$ & 7.888 & 0.091 & 7.400 & 8.129 \\
\hline $\begin{array}{l}\text { Annual Monthly } \\
\text { Precipitation (mm) }\end{array}$ & 91.182 & 2.780 & 82.626 & 102.594 \\
\hline $\begin{array}{l}\text { Summer Monthly } \\
\text { Precipitation }(\mathrm{mm})\end{array}$ & 21.842 & 0.722 & 18.230 & 23.969 \\
\hline $\begin{array}{l}\text { Winter Monthly } \\
\text { Precipitation (mm) }\end{array}$ & 103.163 & 4.187 & 90.309 & 119.474 \\
\hline Property Value (\$100k) & 3.304 & 1.815 & 0.375 & 75.236 \\
\hline House Age (years) & 64.55 & 29.794 & 0 & 165 \\
\hline Lot Area (ha) & 0.068 & 0.092 & 0.004 & 10.360 \\
\hline House Area $\left(\mathbf{m}^{2}\right)$ & 159.222 & 75.203 & 26.013 & $1,885.652$ \\
\hline Coniferous Tree Cover ( $\%)$ & 11.755 & 14.341 & 0 & 100 \\
\hline Deciduous Tree Cover (\%) & 21.631 & 17.309 & 0 & 100 \\
\hline
\end{tabular}


Table 5: Spatial error regression for SFR monthly water use at the household scale

\begin{tabular}{|c|c|c|c|}
\hline \multicolumn{4}{|c|}{ Household $(n=134,666)$} \\
\hline & Annual Use & Summer Use & Winter Use \\
\hline R-square Value & 0.138 & 0.152 & 0.070 \\
\hline $\mathrm{AiC}$ & 214019 & 252925 & 223061 \\
\hline $\begin{array}{l}\text { Maximum } \\
\text { Temperature }\end{array}$ & $0.115 * * *$ & -0.025 & $-0.235^{* * *}$ \\
\hline Precipitation & $0.011 * * *$ & $-0.031 * * *$ & less than 0.001 \\
\hline Property Value & -0.002 & $-0.025^{* * *}$ & $-0.035 * * *$ \\
\hline House Age & $-0.001 * * *$ & $-0.001 * * *$ & $-0.001 * * *$ \\
\hline Lot Area & $0.292 * * *$ & $0.356 * * *$ & $0.105 * * *$ \\
\hline House Area & $0.003 * * *$ & $0.003 * * *$ & $0.002 * * *$ \\
\hline Coniferous Cover & $-0.050 * * *$ & $-0.050 * * *$ & -0.010 \\
\hline Deciduous Cover & $-0.068 * * *$ & $-0.077 * * *$ & less than 0.001 \\
\hline Lambda & $0.055^{* * *}$ & $0.079 * * *$ & $0.038 * * *$ \\
\hline
\end{tabular}

*significant at 0.1

**significant at 0.05

$* * *$ significant at 0.01 
Table 6: Spatial error regression for SFR monthly water use at the census block scale

\begin{tabular}{|c|c|c|c|}
\hline \multicolumn{4}{|c|}{ Census Block $(n=8,289)$} \\
\hline & Annual Use & Summer Use & Winter Use \\
\hline R-square Value & 0.469 & 0.523 & 0.229 \\
\hline $\mathrm{AiC}$ & -4954.36 & -1812.14 & -4360.6 \\
\hline $\begin{array}{l}\text { Maximum } \\
\text { Temperature }\end{array}$ & 0.115 & -0.008 & $-0.242 * * *$ \\
\hline Precipitation & $0.009 * * *$ & $-0.029 * * *$ & less than 0.001 \\
\hline Property Value & $-0.015^{* * *}$ & $0.014 * * *$ & $-0.043^{* * *}$ \\
\hline House Age & $-0.001 * * *$ & $-0.001 * * *$ & $-0.001 * * *$ \\
\hline Lot Area & $0.247 * * *$ & $0.215 * * *$ & $0.158 * * *$ \\
\hline House Area & $0.003 * * *$ & $0.003 * * *$ & $0.002 * * *$ \\
\hline Coniferous Cover & $0.069 * *$ & $0.133 * * *$ & 0.040 \\
\hline Deciduous Cover & $-0.138 * * *$ & $-0.164 * * *$ & -0.009 \\
\hline Lambda & $0.322 * * *$ & $0.422 * * *$ & $0.236 * * *$ \\
\hline
\end{tabular}

\footnotetext{
*significant at 0.1

**significant at 0.05

****significant at 0.01
} 
Table 7: Spatial error regression for SFR monthly water use at the census block group scale

\begin{tabular}{|c|c|c|c|}
\hline \multicolumn{4}{|c|}{ Census Block Group $(n=419)$} \\
\hline & Annual Use & Summer Use & Winter Use \\
\hline R-square Value & 0.857 & 0.845 & 0.646 \\
\hline $\mathrm{AiC}$ & -1007.55 & -736.64 & -992.879 \\
\hline $\begin{array}{l}\text { Maximum } \\
\text { Temperature }\end{array}$ & $0.691 * * *$ & 0.240 & -0.077 \\
\hline Precipitation & 0.004 & $-0.059 * * *$ & -0.003 \\
\hline Property Value & $-0.016 * *$ & -0.017 & $-0.042 * * *$ \\
\hline House Age & less than 0.001 & less than $-0.001^{*}$ & less than 0.001 \\
\hline Lot Area & $0.519 * * *$ & $0.323 * * *$ & $0.248 * * *$ \\
\hline House Area & $0.004 * * *$ & $0.005 * * *$ & $0.002 * * *$ \\
\hline Coniferous Cover & $0.280 * * *$ & $0.414 * * *$ & $0.244 * *$ \\
\hline Deciduous Cover & $0.302 * * *$ & 0.129 & $0.300 * * *$ \\
\hline Lambda & $0.837 * * *$ & $0.755 * * *$ & $0.678 * * *$ \\
\hline
\end{tabular}

\footnotetext{
*significant at 0.1

**significant at 0.05

$* * *$ significant at 0.01
} 
Table 8: Spatial error regression for SFR monthly water use at the census tract scale

\begin{tabular}{|l|c|c|c|}
\hline \multicolumn{4}{|c|}{ Census Tract $(\boldsymbol{n}=142)$} \\
\hline R-square Value & 0.896 & Summer Use & Winter Use \\
\hline AiC & -383.215 & 0.855 & 0.790 \\
\hline Maximum \\
Temperature & $0.682^{* * *}$ & -259.371 & -407.808 \\
\hline Precipitation & 0.004 & 0.142 & 0.095 \\
\hline Property Value & $-0.046 * * *$ & $-0.036 *$ & -0.004 \\
\hline House Age & less than -0.001 & $-0.070 * * *$ & $-0.050 * * *$ \\
\hline Lot Area & $0.352^{* * *}$ & -0.001 & 1 less than 0.001 \\
\hline House Area & $0.004 * * *$ & 0.060 & $0.295 * * *$ \\
\hline Coniferous Cover & 0.155 & $0.007 * * *$ & $0.002 * * *$ \\
\hline Deciduous Cover & $0.302 * *$ & $0.328 *$ & 0.179 \\
\hline Lambda & $0.826 * * *$ & -0.315 & $0.453 * * *$ \\
\hline
\end{tabular}

\footnotetext{
*significant at 0.1

**significant at 0.05

****significant at 0.01
} 
Table 9: Spatial error regression for SFR monthly water use at the neighborhood scale

\begin{tabular}{|c|c|c|c|}
\hline \multicolumn{4}{|c|}{ Neighborhood $(n=111)$} \\
\hline & Annual Use & Summer Use & Winter Use \\
\hline R-square Value & 0.818 & 0.806 & 0.634 \\
\hline $\mathrm{AiC}$ & -228.696 & -144.694 & -266.027 \\
\hline $\begin{array}{l}\text { Maximum } \\
\text { Temperature }\end{array}$ & 0.159 & 0.088 & $-0.320 * * *$ \\
\hline Precipitation & 0.005 & $-0.048 *$ & -0.002 \\
\hline Property Value & $-0.044 * * *$ & $-0.047 * * *$ & $-0.039 * * *$ \\
\hline House Age & -0.001 & -0.001 & $-0.001 * *$ \\
\hline Lot Area & $0.583 * * *$ & $0.773 * * *$ & -0.122 \\
\hline House Area & $0.004 * * *$ & $0.005 * * *$ & $0.002 * * *$ \\
\hline Coniferous Cover & 0.156 & -0.026 & $0.327 * * *$ \\
\hline Deciduous Cover & $-0.280 *$ & -0.167 & 0.040 \\
\hline Lambda & 0.119 & $0.446^{* * *}$ & -0.105 \\
\hline
\end{tabular}

\footnotetext{
*significant at 0.1

**significant at 0.05

***significant at 0.01
} 
Table 10: Multi-level regression for SFR summer monthly water use at the household scale using census tract and census tract plus household variables

\begin{tabular}{|c|c|c|}
\hline & $\begin{array}{c}\text { Census Tract Variables } \\
(n=134,666)\end{array}$ & $\begin{array}{l}\text { Census Tract and Household } \\
\text { Variables }(n=134,666)\end{array}$ \\
\hline $\begin{array}{l}\text { Adjusted R-square } \\
\text { Value }\end{array}$ & 0.067 & 0.165 \\
\hline $\mathbf{A i C}$ & 265422 & 250438 \\
\hline CT Summer Water Use & $0.030 * * *$ & $0.030 * * *$ \\
\hline $\begin{array}{l}\text { CT Summer Max } \\
\text { Temp }\end{array}$ & $0.123 * * *$ & -0.465 \\
\hline $\begin{array}{l}\text { CT Summer } \\
\text { Precipitation }\end{array}$ & -0.004 & $0.025 * *$ \\
\hline CT Property Value & $-0.037 * * *$ & $-0.114 * * *$ \\
\hline CT House Age & less than 0.001 & less than $0.001^{* *}$ \\
\hline CT Lot Area & $-0.687 * * *$ & $-0.754 * * *$ \\
\hline CT House Area & $0.002 * * *$ & less than 0.001 \\
\hline CT Coniferous Cover & $0.218 * * *$ & $0.336 * * *$ \\
\hline CT Deciduous Cover & $-0.292 * * *$ & $-0.251 * * *$ \\
\hline Summer Max Temp & & 0.082 \\
\hline Summer Precipitation & & $-0.029 * *$ \\
\hline Property Value & & $-0.077 * * *$ \\
\hline House Age & & less than -0.001 \\
\hline Lot Area & & $0.067 * * *$ \\
\hline House Area & & $0.002 * * *$ \\
\hline Coniferous Cover & & $0.118 * * *$ \\
\hline Deciduous Cover & & $-0.041 * * *$ \\
\hline
\end{tabular}

*significant at 0.1

**significant at 0.05

****significant at 0.01 
Table 11: Multi-level regression for SFR summer monthly water use at the household scale using neighborhood and neighborhood plus household variables

\begin{tabular}{|c|c|c|}
\hline & $\begin{array}{c}\text { Neighborhood } \\
\text { Variables } \\
(n=134,666)\end{array}$ & $\begin{array}{c}\text { Neighborhood and } \\
\text { Household Variables } \\
(n=134,666)\end{array}$ \\
\hline $\begin{array}{l}\text { Adjusted R-square } \\
\text { Value }\end{array}$ & 0.074 & 0.169 \\
\hline $\mathrm{AiC}$ & 264370 & 249873 \\
\hline N Summer Water Use & $0.799 * * *$ & $0.803 * * *$ \\
\hline N Summer Max Temp & $-0.121 * * *$ & $-0.103 * * *$ \\
\hline $\begin{array}{l}\text { N Summer } \\
\text { Precipitation }\end{array}$ & -0.005 & $0.015^{*}$ \\
\hline N Property Value & $-0.016 * * *$ & $-0.095 * * *$ \\
\hline N House Age & less than -0.001 & less than 0.001 \\
\hline N Lot Area & $-0.125^{*}$ & $-0.176 * * *$ \\
\hline N House Area & $0.001 * * *$ & $-0.001 * * *$ \\
\hline N Coniferous Cover & $-0.132 * * *$ & 0.030 \\
\hline N Deciduous Cover & -0.017 & -0.115 \\
\hline Summer Max Temp & & $0.186 * * *$ \\
\hline Summer Precipitation & & $-0.018 * *$ \\
\hline Property Value & & $-0.074 * * *$ \\
\hline House Age & & less than -0.001 \\
\hline Lot Area & & $0.060 * * *$ \\
\hline House Area & & $0.002 * * *$ \\
\hline Coniferous Cover & & $-0.114 * * *$ \\
\hline Deciduous Cover & & $-0.0378 * * *$ \\
\hline
\end{tabular}

*significant at 0.1

** significant at 0.05

$* * *$ significant at 0.01 
Figure 1: The map below shows the location of Portland within the state of Oregon, while the inset map provides a closer view of the Portland city limits as well as a general understanding of land use through aerial photography.

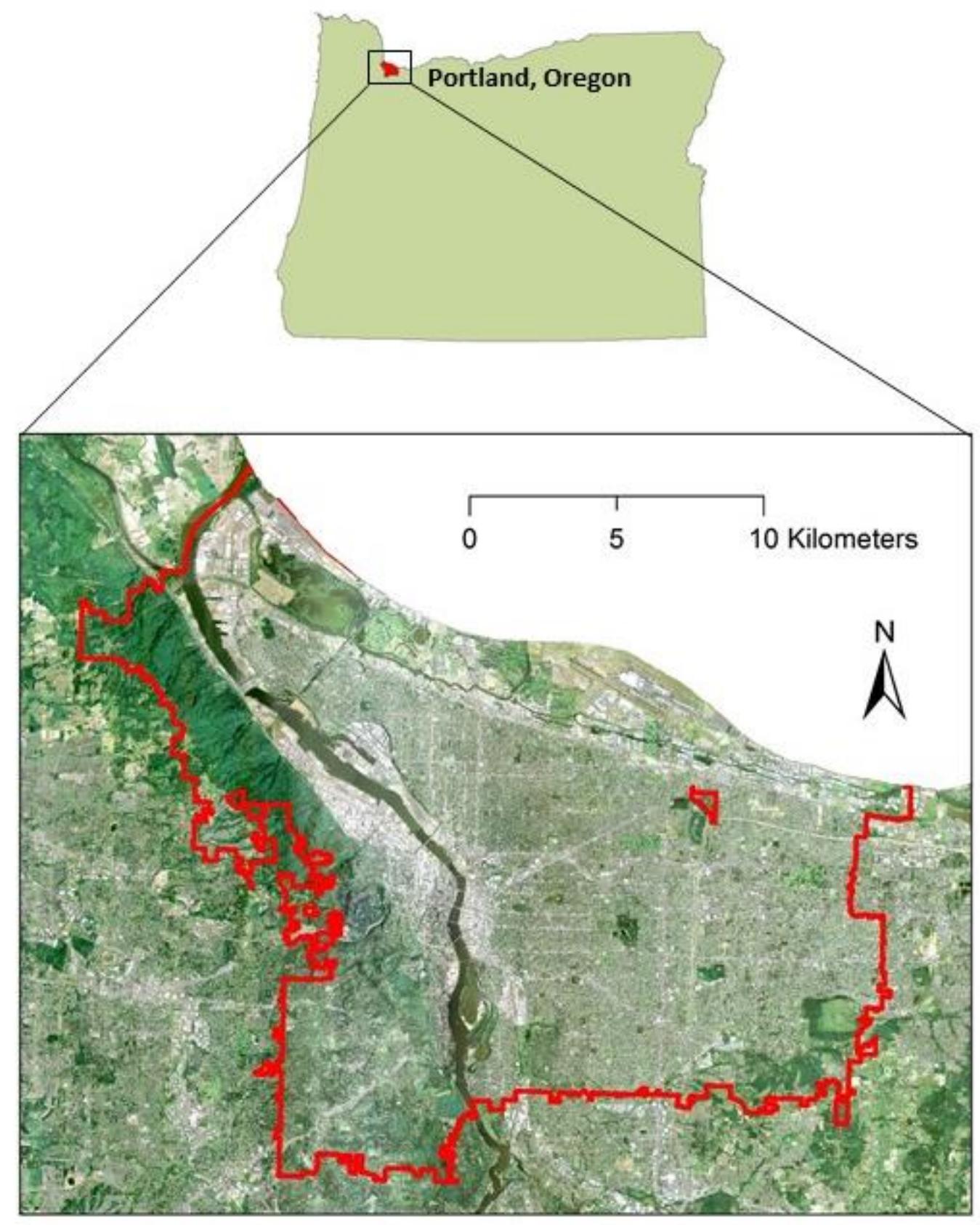


Figure 2: The chart below provides a simplified view of how the household water use and exploratory variables were aggregated to the census block, census block group, census tract, and neighborhood scales.

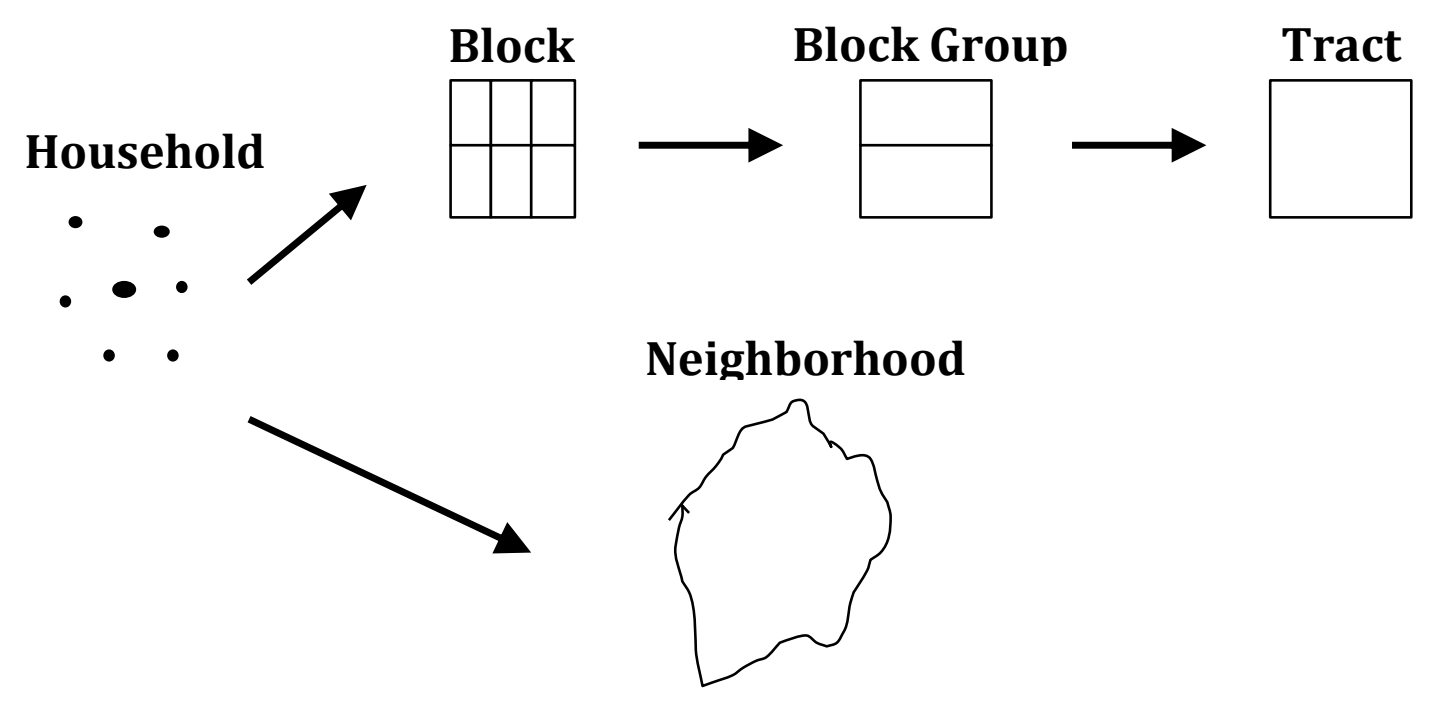


Figure 3: The below figure displays 2011 mean monthly SFR water use at the a) census block, b) census block group, c) census tract, and d) neighborhood scales for Portland, Oregon.

a)

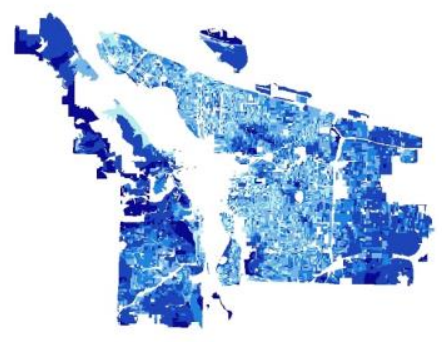

c)

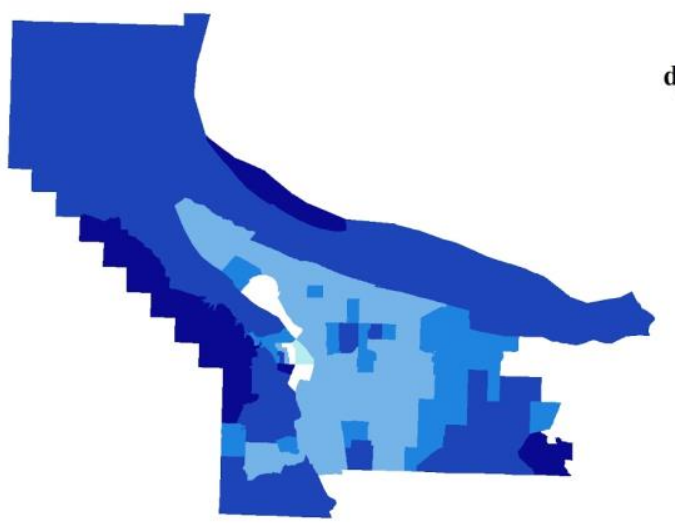

b)

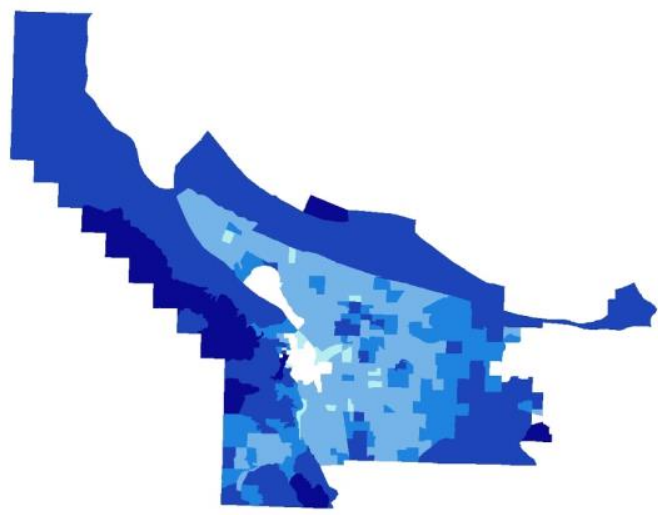

d)

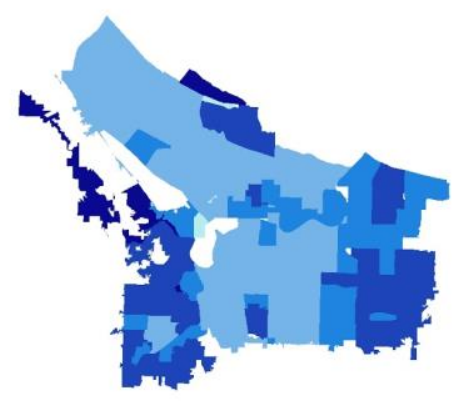

2011 Mean Monthly Annual Water Use (kL)

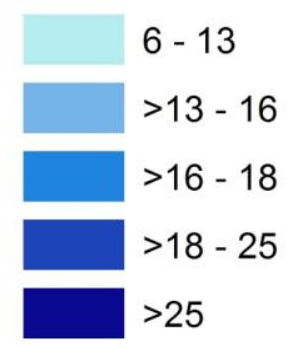

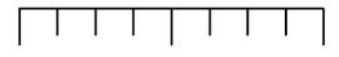

$\begin{array}{llll}0 & 5 & 10 & 20 \text { Kilometers }\end{array}$ 
Figure 4: The below figure displays 2011 mean summer monthly SFR water use at the a) census block, b) census block group, c) census tract, and d) neighborhood scales for Portland, Oregon.

a)

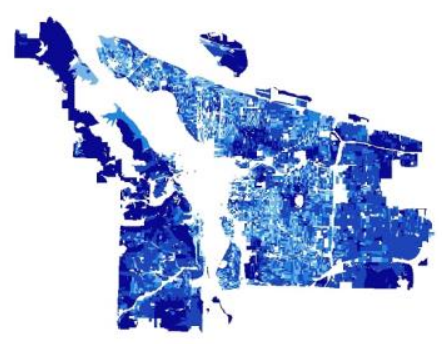

c)

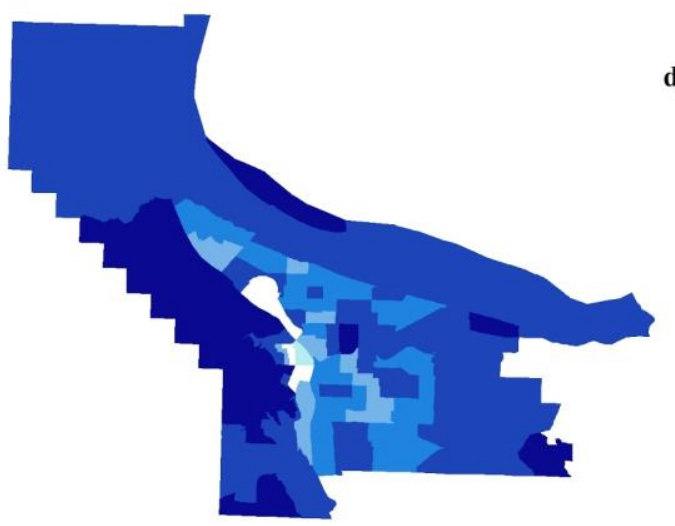

b)

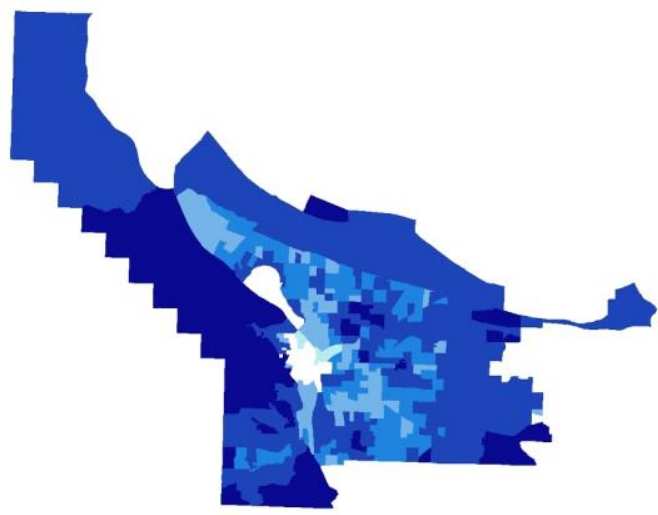

d)

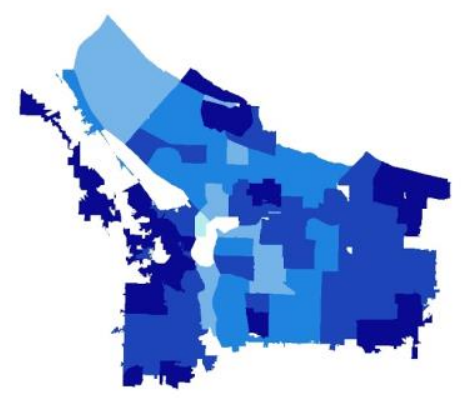

\section{Mean Monthly}

Summer Water Use (kL)
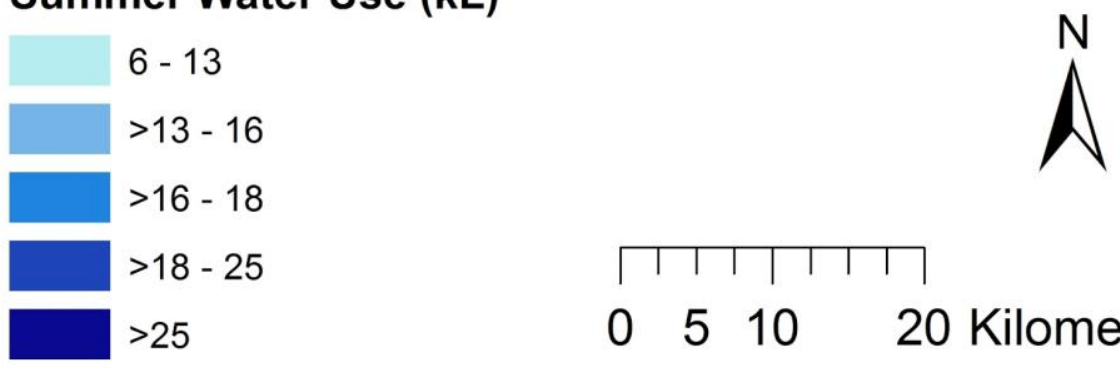

$\begin{array}{llll}0 & 5 & 10 & 20 \text { Kilometers }\end{array}$ 
Figure 5: The below figure displays 2011 mean winter monthly SFR water use at the a) census block, b) census block group, c) census tract, and d) neighborhood scales for Portland, Oregon.

a)

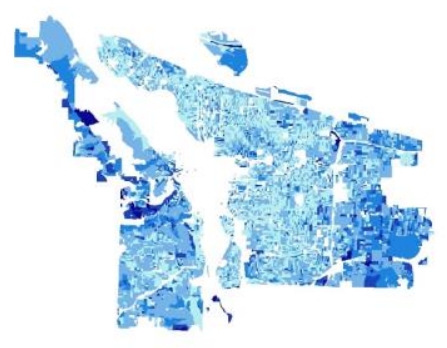

c)

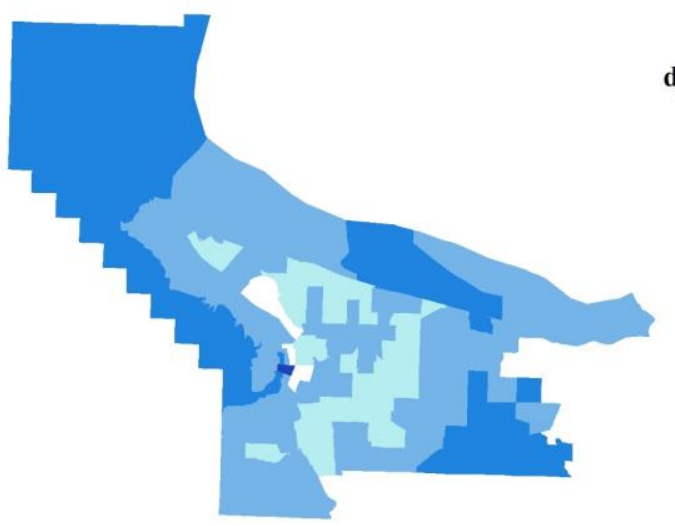

b)

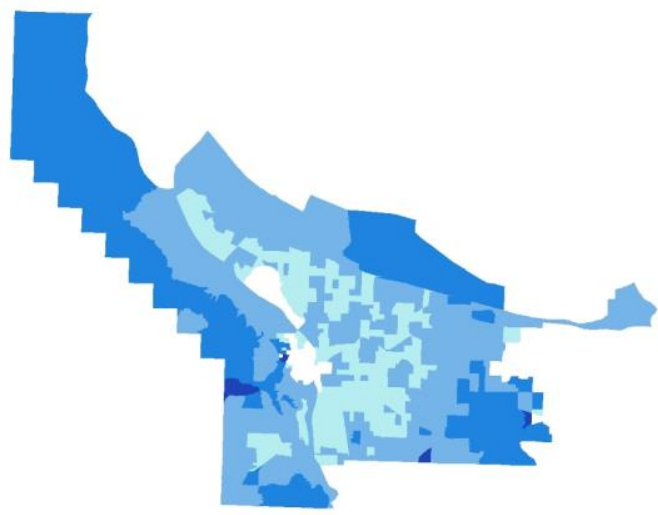

d)

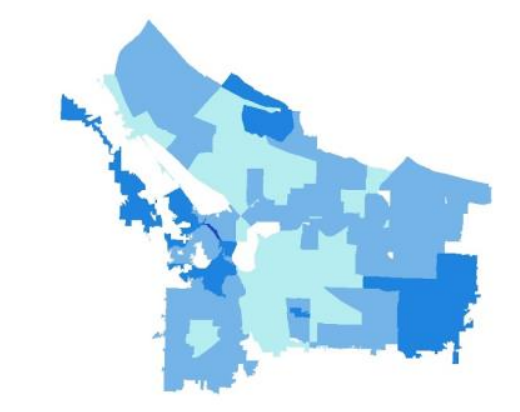

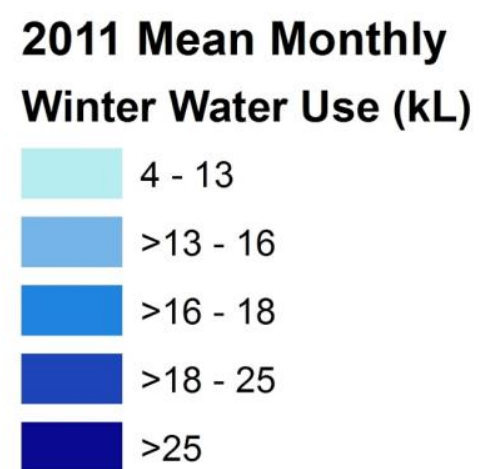

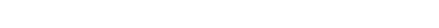


Figure 6: The multi-level regression models used in this study showing how household, neighborhood, and census tract characteristics influence household level water use in Portland, Oregon.

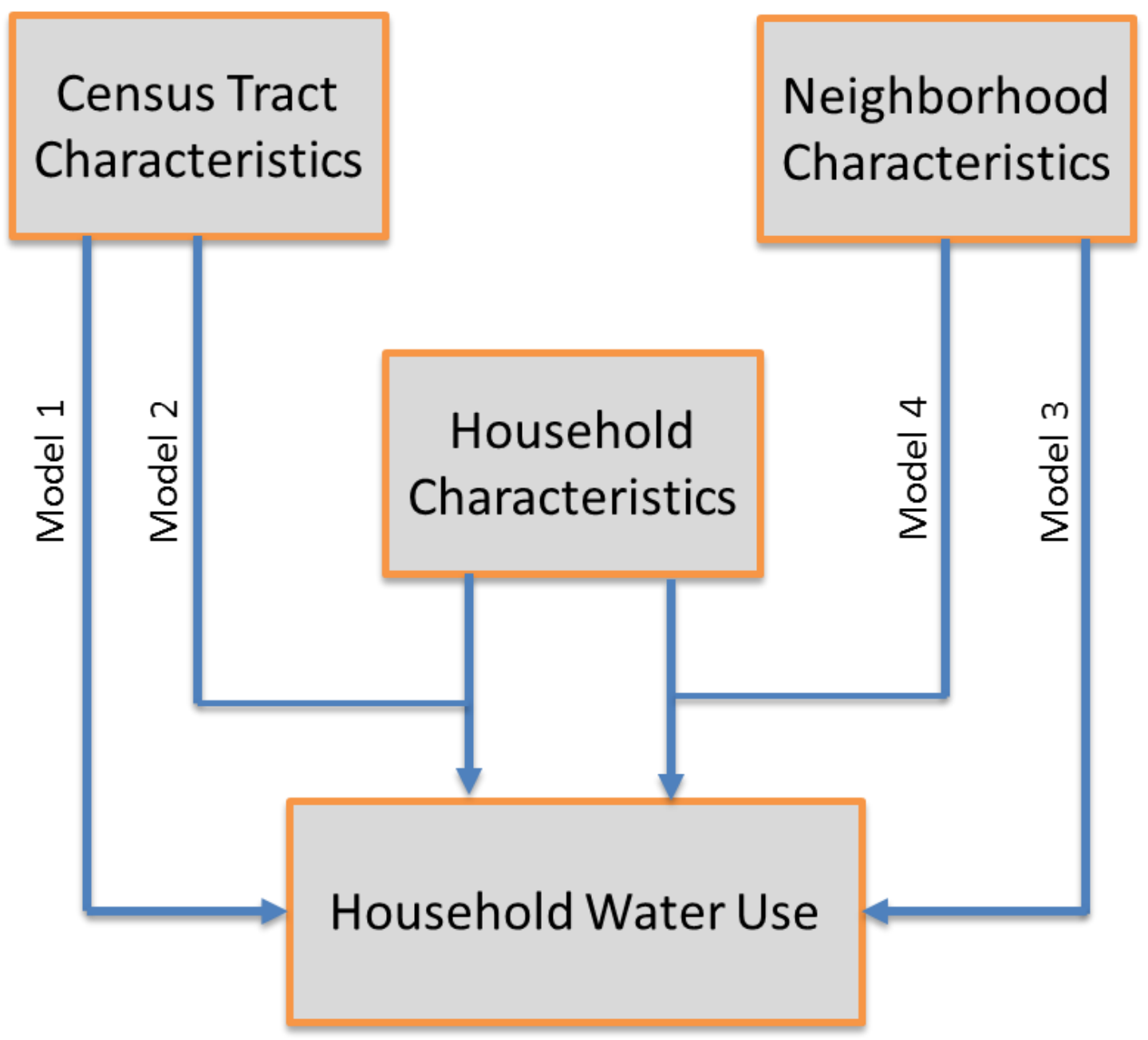


Figure 7: Local Moran's I clusters for a) annual, b) summer, and c) winter SFR water use at the census block scale

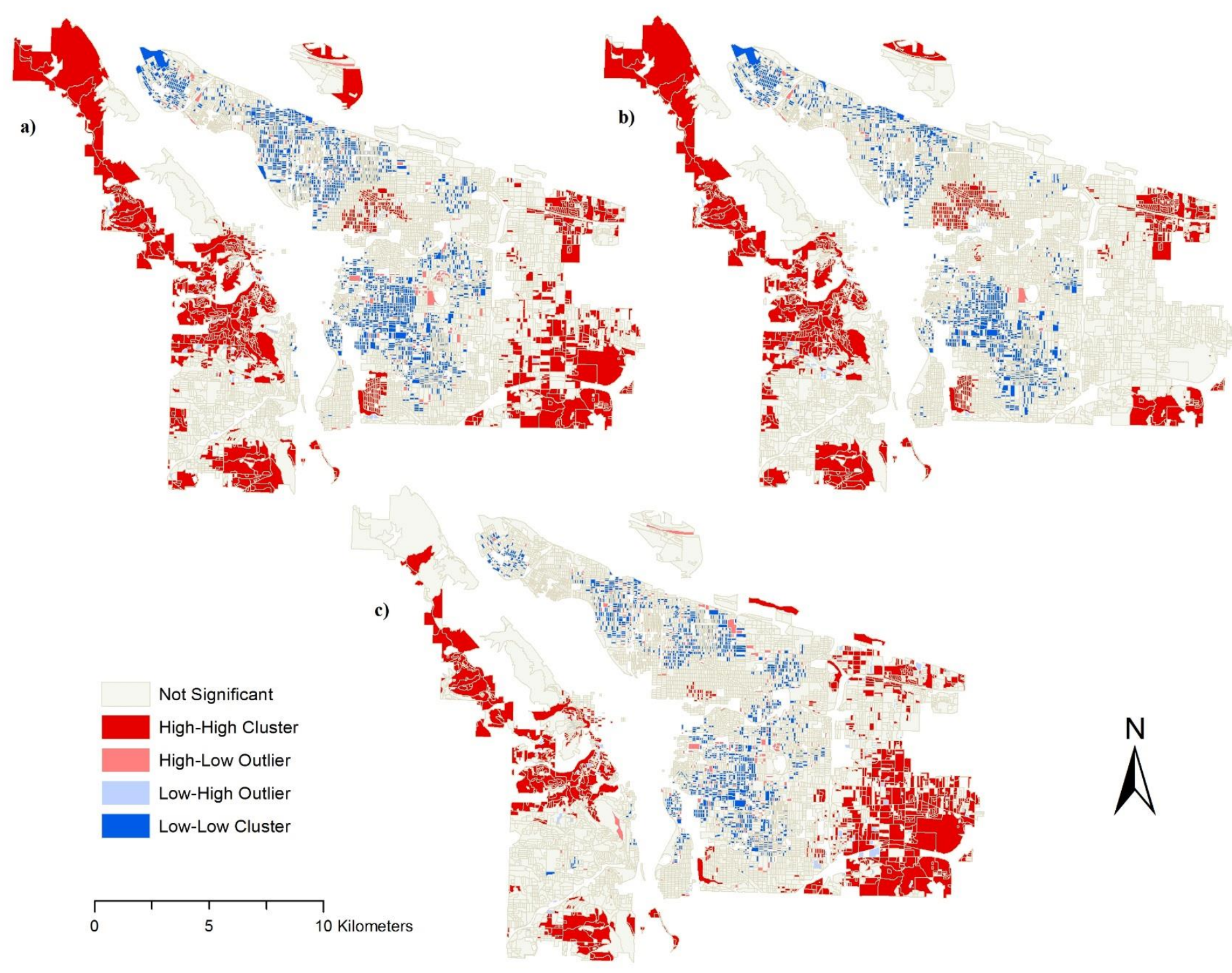


Figure 8: Getis-Ord Gi* hot spots for a) annual, b) summer, and c) winter SFR water use at the census block scale

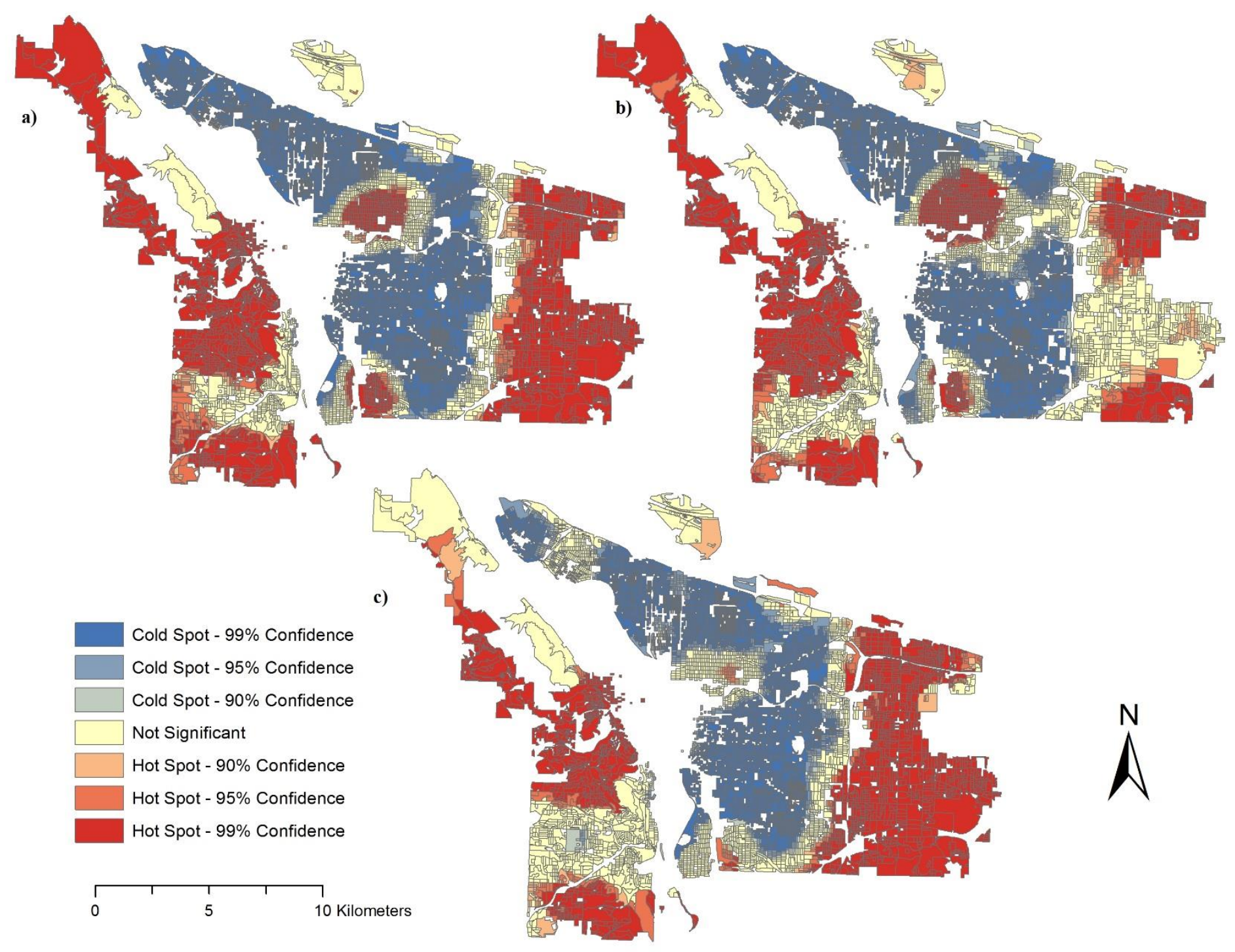


Figure 9: Local Moran's I clusters for a) annual, b) summer, and c) winter SFR water use at the census block group scale
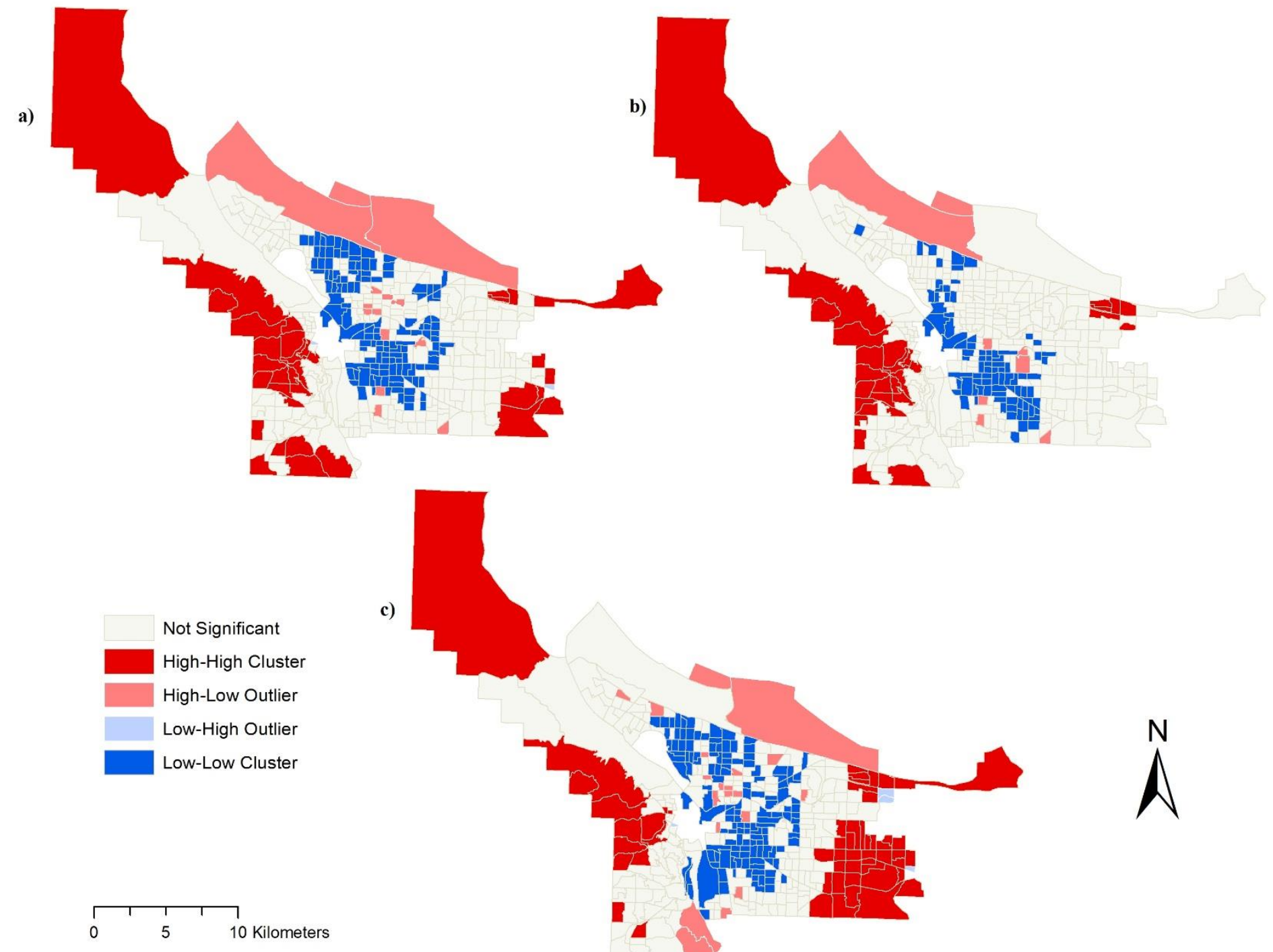

c)
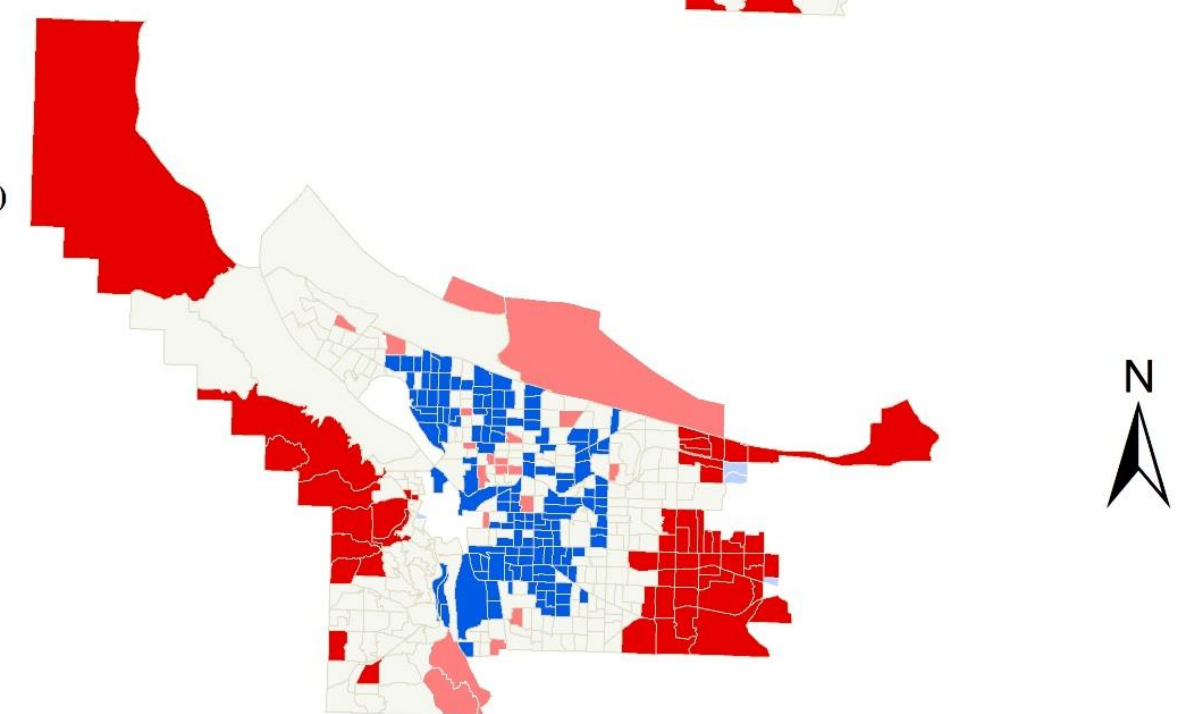
Figure 10: Getis-Ord Gi* hot spots for a) annual, b) summer, and c) winter SFR water use at the census block group scale

a)

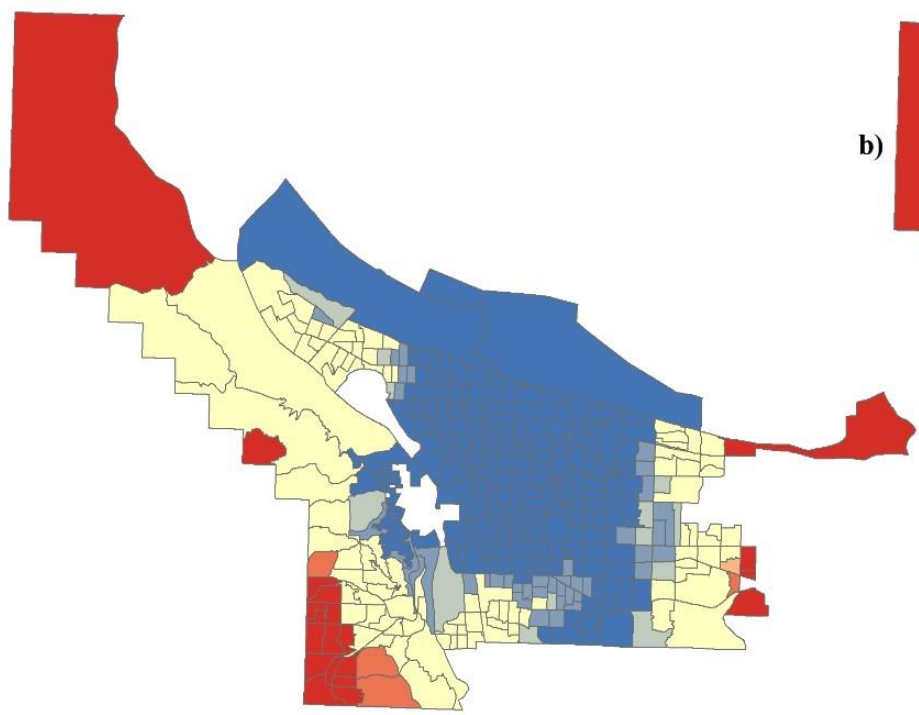

Cold Spot - 99\% Confidence Cold Spot - 95\% Confidence Cold Spot - 90\% Confidence Not Significant

Hot Spot - 90\% Confidence Hot Spot - 95\% Confidence Hot Spot - 99\% Confidence

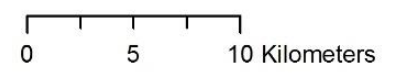

c)
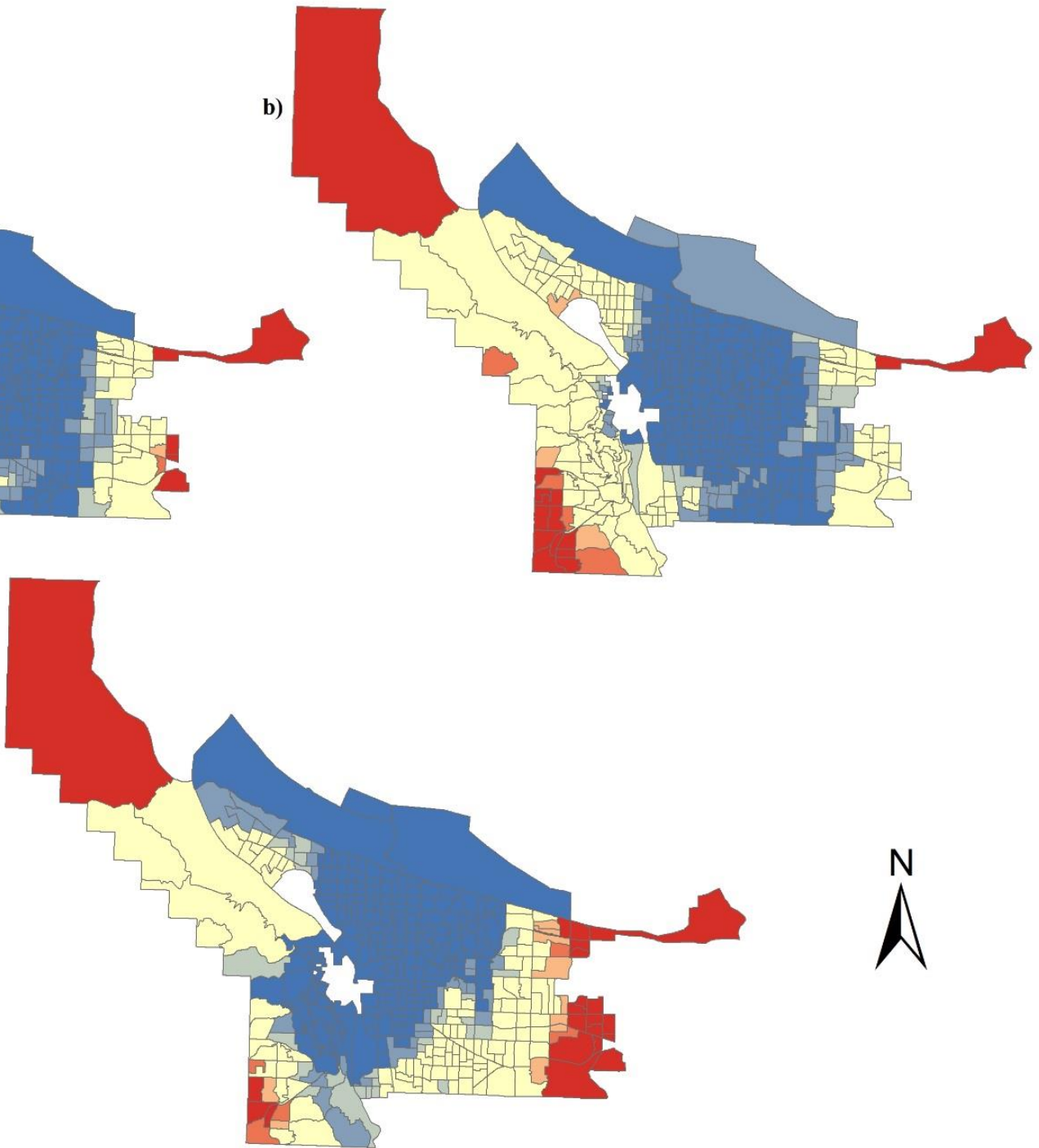
Figure 11: Local Moran's I clusters for a) annual, b) summer, and c) winter SFR water use at the census tract scale

a)

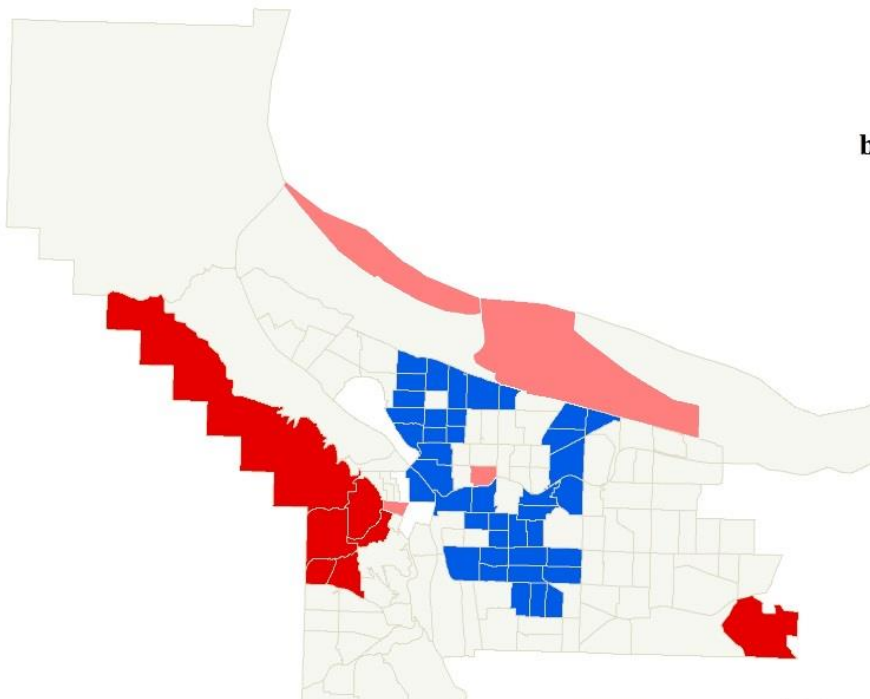

c)

Not Significant

High-High Cluster

High-Low Outlier

Low-High Outlier

Low-Low Cluster

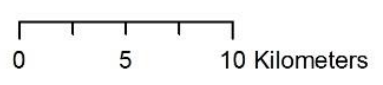

b)
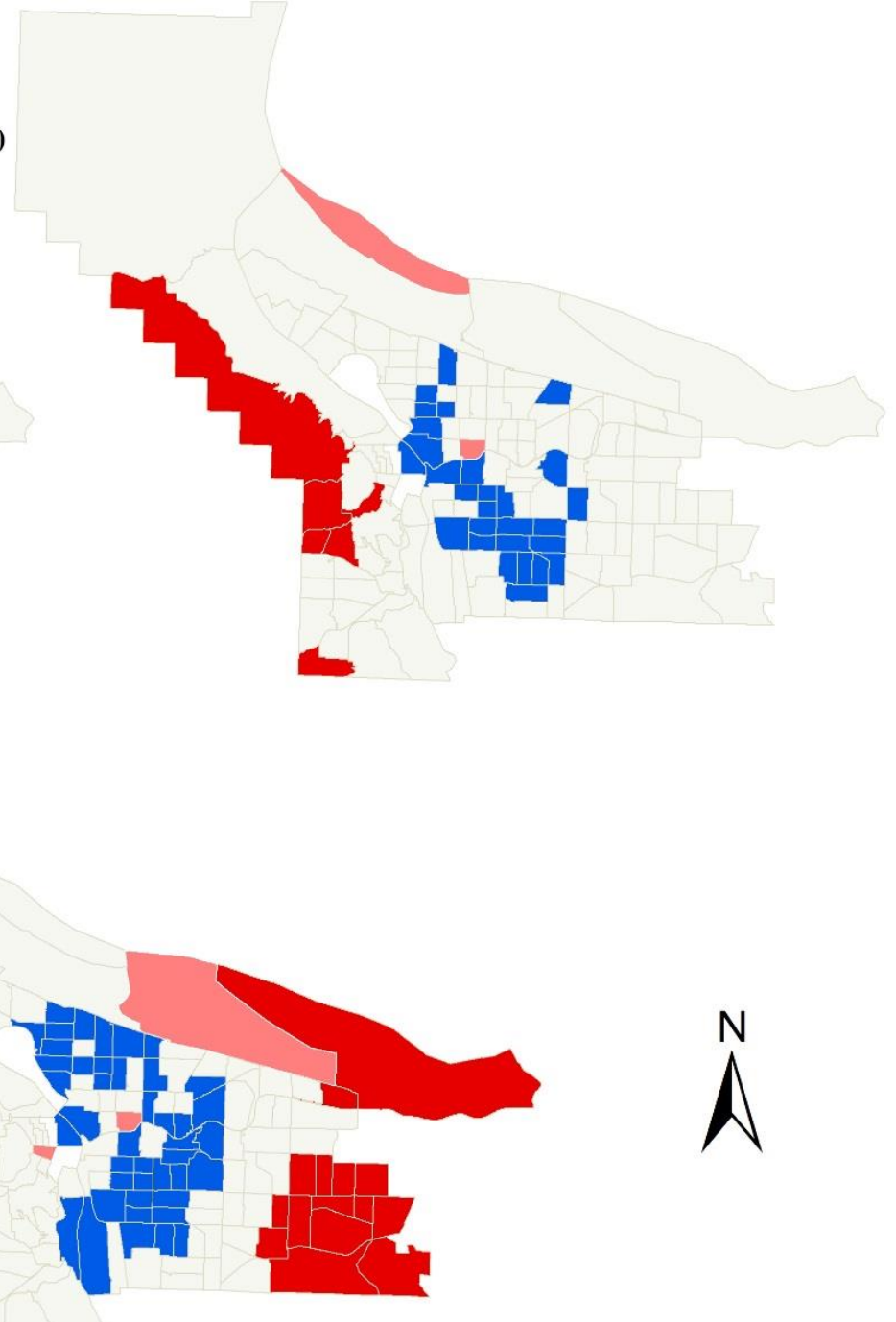
Figure 12: Getis-Ord Gi* hot spots for a) annual, b) summer, and c) winter SFR water use at the census tract scale

a)

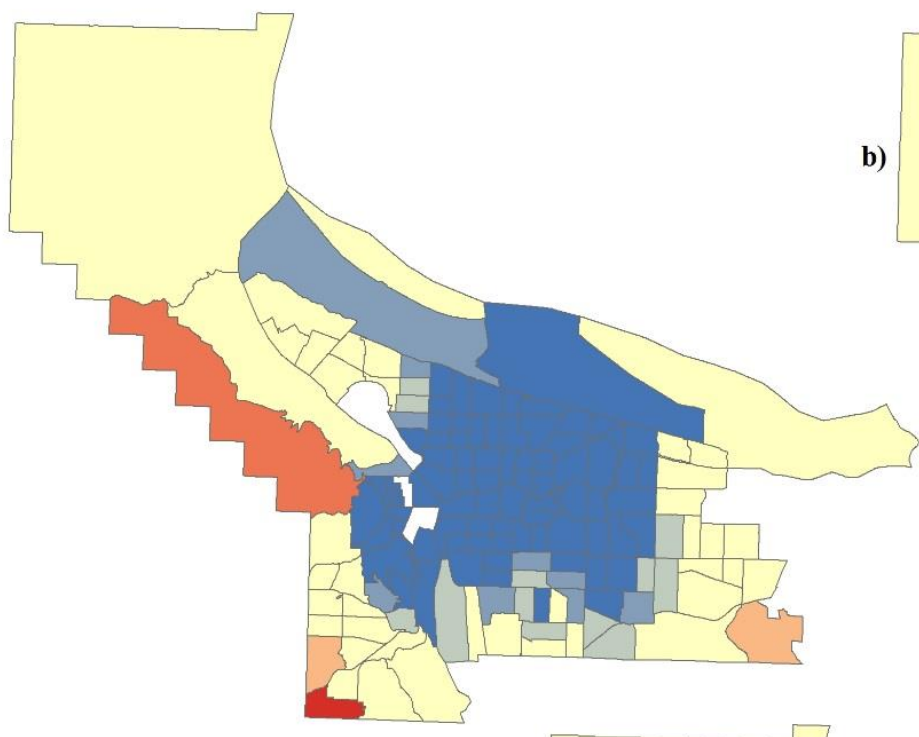

Cold Spot - 99\% Confidence Cold Spot - 95\% Confidence Cold Spot - 90\% Confidence Not Significant

Hot Spot - 90\% Confidence Hot Spot - 95\% Confidence Hot Spot - 99\% Confidence

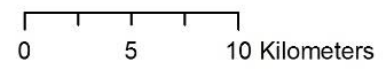

c)
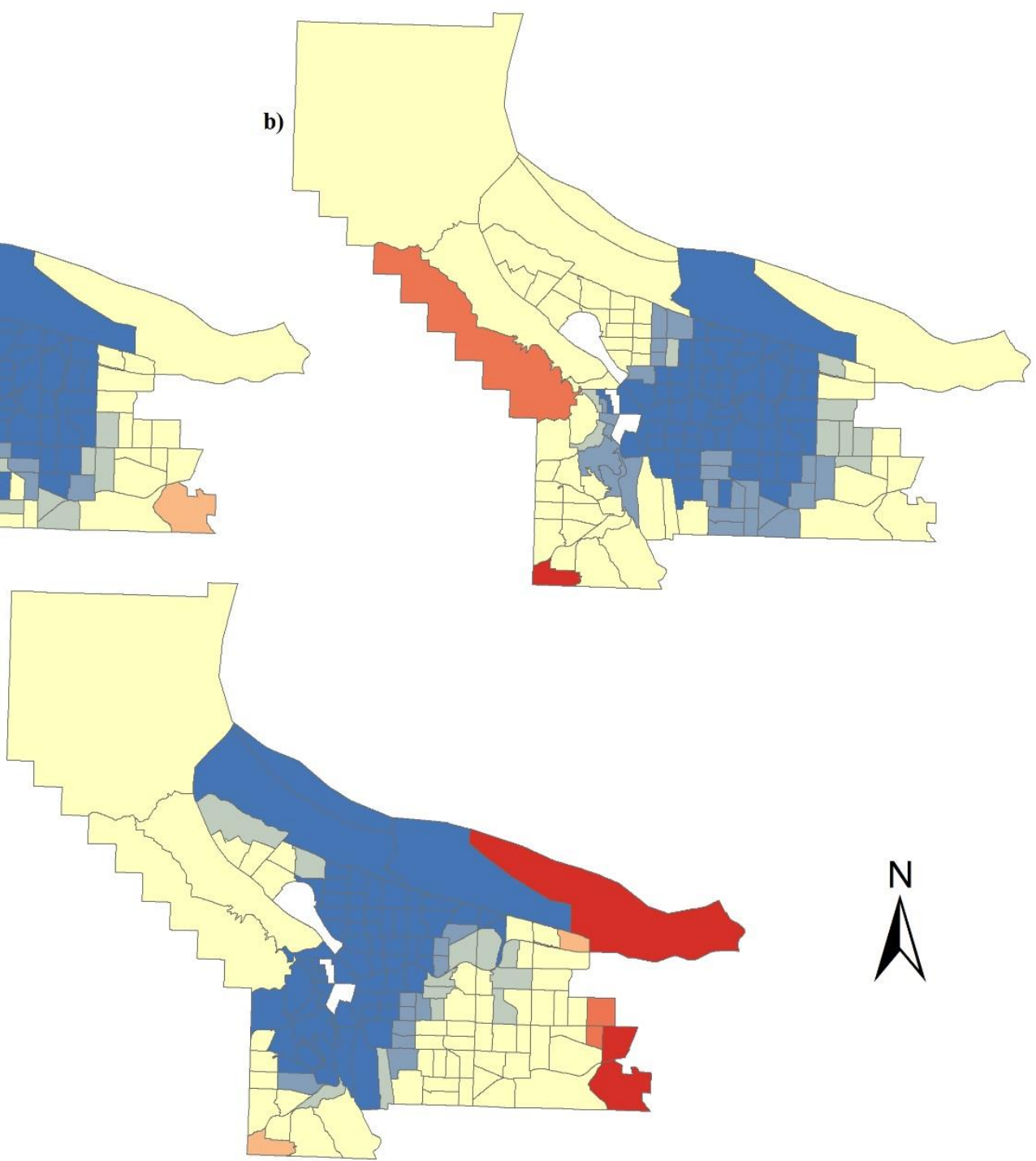
Figure 13: Local Moran's I clusters for a) annual, b) summer, and c) winter SFR water use at the neighborhood scale

a)

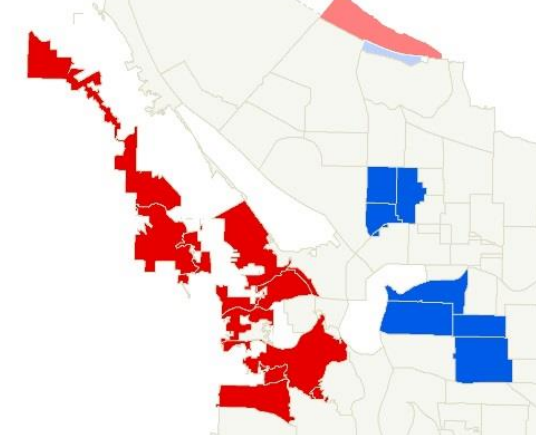

b)

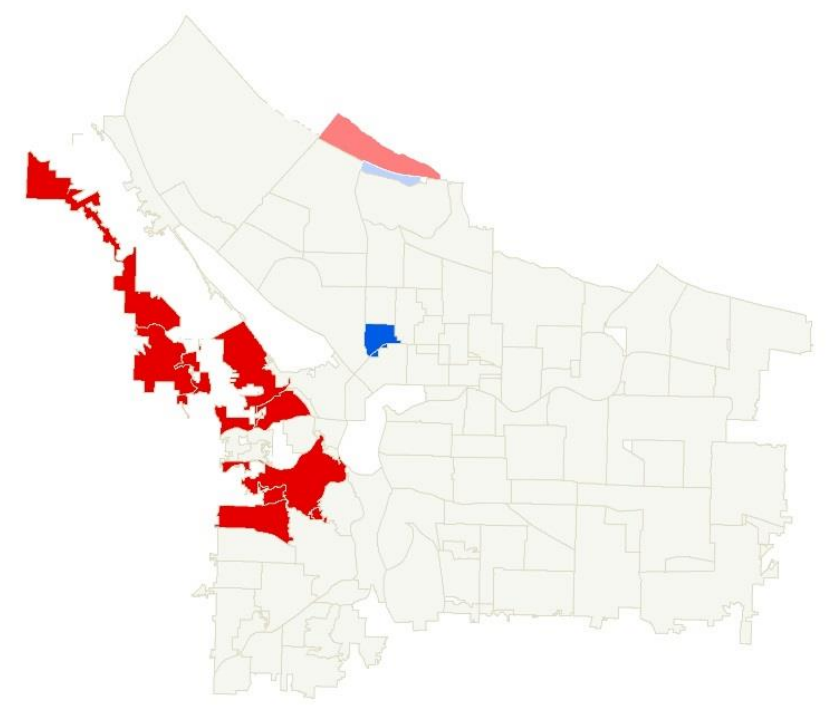

Not Significant

High-High Cluster High-Low Outlier

Low-High Outlier

Low-Low Cluster

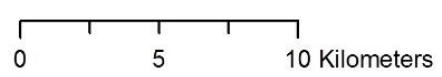

c)

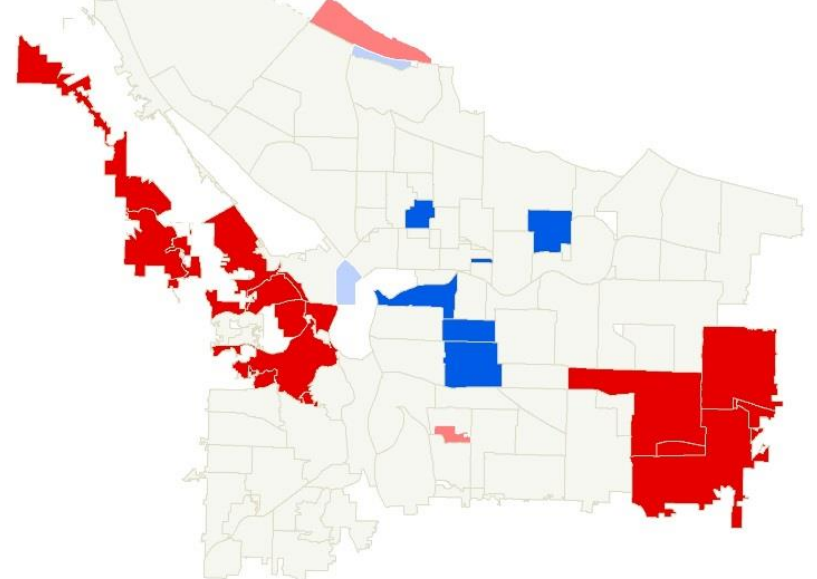

N 
Figure 14: Getis-Ord Gi* hot spots for a) annual, b) summer, and c) winter SFR water use at the neighborhood scale

a)

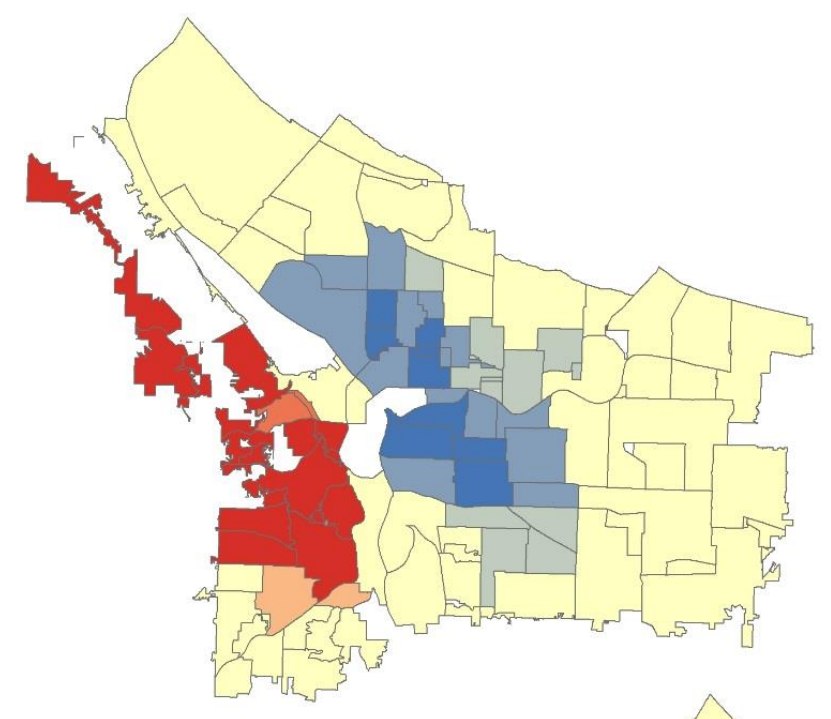

b)

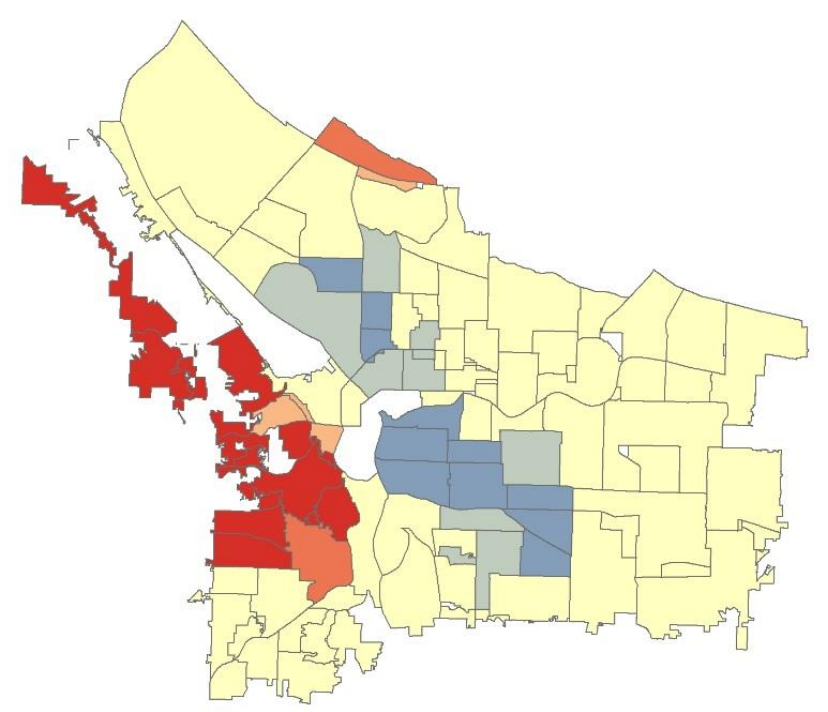

Cold Spot - 99\% Confidence Cold Spot - 95\% Confidence Cold Spot - 90\% Confidence Not Significant

Hot Spot - 90\% Confidence Hot Spot - 95\% Confidence Hot Spot - 99\% Confidence

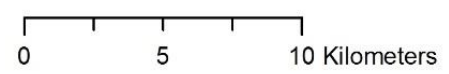

c)

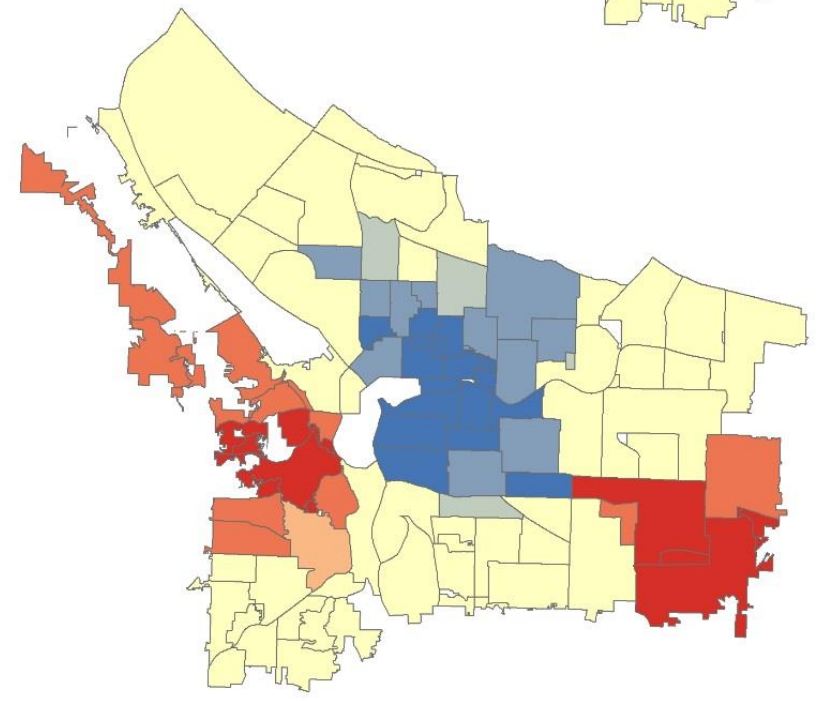

« 
References

Adamowski, J., H. F. Chan, S. O. Prasher, B. Ozga-Zielinski, and A. Sliusarieva. 2012. Comparison of multiple linear and nonlinear regression, autoregressive integrated moving average, artificial neural network, and wavelet artificial neural network methods for urban water demand forecasting in Montreal, Canada. Water Resources Research 48(1).

Ashoori, N., D. A. Dzombak, and M. J. Small. 2016. Modeling the Effects of Conservation, Demographics, Price, and Climate on Urban Water Demand in Los Angeles, California. Water Resources Management 30: 5247-62.

Baerenklau, K. A., K. A. Schwabe, and A. Dinar. 2014. The Residential Water Demand Effect of Increasing Block Rate Water Budgets. Land Economics 90(4): 683-99.

Bates, B. C., Z. W. Kundzewicz, S. Wu, and J. P. Palutikof. 2008. Climate Change and Water. Technical Paper of the Intergovernmental Panel on Climate Change. IPCC Secretariat: Geneva, Switzerland.

Boxall, B. 2017. Is the great California drought finally ending?. Los Angeles Times, 12 January: n.p.

Brelsford, C. and J. K. Abbott. 2017. Growing into Water Conservation? Decomposing the Drivers of Reduced Water Consumption in Las Vegas, NV. Ecological Economics 133: 99-110.

Breyer, B., H. Chang, and G. H. Parandvash. 2012. Land-use, temperature, and singlefamily residential water use patterns in Portland, Oregon and Phoenix, Arizona. Applied Geography 35: 142-51.

Browne, A. L., W. Medd, and B. Anderson. 2013. Developing Novel Approaches to Tracking Domestic Water Demand Under Uncertainty - A Reflection on the "Up Scaling" of Social Science Approaches in the United Kingdom. Water Resources Management 27(4): 1013-35.

Butler, L. J., M. K. Scammell, and E. B. Benson. 2016. The Flint, Michigan, Water Crisis: A Case Study in Regulatory Failure and Environmental Injustice. Environmental Justice 9(4): 93-7.

Cardell-Oliver, R. 2013. Water use signature patterns for analyzing household consumption using medium resolution meter data. Water Resources Research 49: 8589-99.

Chang, H., G. H. Parandvash, and V. Shandas. 2010. Spatial variations of single-family residential water consumption in Portland, Oregon. Urban Geography 31: 953-72. 
Chang, H., S. Praskievicz, and H. Parandvash. 2014. Sensitivity of urban water consumption to weather climate variability at multiple temporal scales: The case of Portland. International Journal of Geospatial and Environmental Research 1(1): 7 .

Chang, H. and M. R. Bonnette. 2016. Climate change and water-related ecosystem services: impacts of drought in California, USA. Ecosystem Health and Sustainability 2(12).

City of Portland. 2016. Deciduous and Coniferous Tree Cover Shapefile.

City of Portland Bureau of Planning and Sustainability (BPS). 2014. Neighborhoods Boundary Shapefile.

Dark, S. J. and D. Bram. 2007. The modifiable areal unit problem (MAUP) in physical geography. Progress in Physical Geography 31(5): 471-9.

de Maria André, D. and J. R. Carvalho. 2014. Spatial Determinants of Urban Residential Water Demand in Fortaleza, Brazil. Water Resources Management 28: 2401-14.

Dharmaratna, D. and E. Harris. 2012. Estimating Residential Water Demand Using the Stone-Geary Functional Form: The Case of Sri Lanka. Water Resources Management 26: 2283-99.

Dijk, A., H. E. Beck, R. S. Crosbie, R. A. Jeu, Y. Y. Liu, G. M. Podger, and N. R. Viney. 2013. The Millennium Drought in southeast Australia (2001 - 2009): natural and human causes and implications for water resources, ecosystems, economy, and society. Water Resources Research 49(2): 1040-57.

Easterling, W. E. and C. Polsky. 2004. Crossing the Divide: Linking Global and Local Scales in Human-Environment Systems. In Scale \& Geographic Inquiry: Nature, Society, and Method, eds. E. Sheppard and R. B. McMaster, 66-85. Oxford: Blackwell Publishing.

Fielding, K. S., S. Russell, A. Spinks, and A. Mankad. 2012. Determinants of household water conservation: The role of demographic, infrastructure, behavior, and psychosocial variables. Water Resources Research 48(10): W10510.

Fotheringham, A. S. and D. W. S. Wong. 1991. The modifiable areal unit problem in multivariate statistical analysis. Environment and Planning A 23(7): 1025-44.

Fullerton Jr., T. M., K. C. White, W. D. Smith, and A. G. Walke. 2013. An empirical analysis of Halifax municipal water consumption. Canadian Water Resources Journal 38(2): 148-58. 
Gage, E. and D. J. Cooper. 2015. The Influence of Land Cover, Vertical Structure, and Socioeconomic Factors on Outdoor Water Use in a Western US City. Water Resources Management 29(10): 3877-90.

Grafton, R. Q., M. B. Ward, H. To, and T. Kompas. 2011. Determinants of residential water consumption: Evidence and analysis from a 10-country household survey. Water Resources Research 47: W08537.

Halper, E. B., S. Dall'erba, R. H. Bark, C. A. Scott, and S. R. Yool. 2015. Effects of irrigated parks on outdoor residential water use in a semi-arid city. Landscape and Urban Planning 134: 210-20.

Harlan, S. L., S. T. Yabiku, L. Larsen, and A. J. Brazel. 2009. Household water consumption in an arid city: affluence, affordance, and attitudes. Society and Natural Resources 22(8): 691-709.

Hejazi, M., J. Edmonds, L. Clarke, P. Kyle, E. Davies, V. Chaturvedi, M. Wise, P. Patel, J. Eom, K. Calvin, R. Moss, and S. Kim. 2014. Long-term global water projections using six socioeconomic scenarios in an integrated assessment modeling framework. Technological Forecasting \& Social Change 81: 205-26.

Hlásny, T., C. Mátyás, R. Seidl, L. Kulla, K. Merganičová, J. Trombik, L. Dobor, Z. Barcza, and B. Konôpka. 2014. Climate change increases the drought risk in Central European forests: What are the options for adaptation? Forestry Journal 60(1): 5-18.

Hong, C. and H. Chang. 2014. Uncovering the Influence of Household Sociodemographic and Behavioral Characteristics on Summer Water Consumption in the Portland Metropolitan Area. International Journal of Geospatial and Environmental Research 1(2): 2.

Hornberger, G. M., D. J. Hess, and J. Gilligan. 2015. Water conservation and hydrological transitions in cities in the United States. Water Resources Research 51: 4635-49.

House-Peters, L., B. Pratt, and H. Chang. 2010. Effects of Urban Spatial Structure, Sociodemographics, and Climate on Residential Water Consumption in Hillsboro, Oregon. Journal of the American Water Resources Association 46(3): 461-72.

House-Peters, L. and H. Chang. 2011. Urban water demand modeling: Review of concepts, methods, and organizing principles. Water Resources Research 47(5). 
IPCC (Intergovernmental Panel on Climate Change). 2014. Summary for Policy makers. In: Climate Change 2014: Impacts, Adaptation, and Vulnerability. Contribution of Working Group II to the Fifth Assessment Report of the Intergovernmental Panel on Climate Change. Cambridge University Press: Cambridge, United Kingdom and New York.

Janmaat, J. 2013. Spatial patterns and policy implications for residential water use: An example using Kelowna, British Columbia. Water Resources and Economics 1: 319.

Johnson, W. B. 2016. Is Arizona's drought over? Not so fast. The Arizona Republic, 20 January: n.p.

Jorgensen, B. S., J. F. Martin, M. W. Pearce, and E. M. Willis. 2014. Predicting household water consumption with individual-level variables. Environment and Behavior 46(7): 827-97.

Kwan, M. 2012. The Uncertain Geographic Context Problem. Annals of the Association of American Geographers 102(5): 958-68.

Lee, J. 2016. Residential water demand analysis of a Low-Income Rate Assistance Program in California, United States. Water and Environment Journal 30: 49-61.

Liu, Y., J. Zhao, and Z. Wang. 2015. Identifying determinants of urban water use using data mining approach. Urban Water Journal 12(8): 618-30.

Mini, C., T. S. Hogue, and S. Pincetl. 2014. Patterns and controlling factors of residential water use in Los Angeles, California. Water Policy 16: 1054-69.

Minnesota Population Center. 2011. National Historical Geographic Information System: Version 2.0. Minneapolis, MN: University of Minnesota.

Nam, W. et al. 2015. Drought hazard assessment in the context of climate change for South Korea. Agricultural Water Management 160: 106-17.

Openshaw, S. 1984. Ecological fallacies and the analysis of areal census data. Environment and Planning A 16(1): 17-31.

Oregon METRO Regional Land Information System (RLIS). 2011. Household characteristic variables for Portland, OR in 2011.

Ouyang, Y., E. A. Wentz, B. L. Ruddell, and S. L. Harlan. 2014. A Multi-scale Analysis of Single-family Residential Water Use in the Phoenix Metropolitan Area. Journal of the American Water Resources Association 50(2): 448-67. 
Ozan, L. A. and K. A. Alsharif. 2013. The effectiveness of water irrigation policies for residential turfgrass. Land Use Policy 31: 378-84.

Panagopoulos, G. P. 2014. Assessing the impacts of socio-economic and hydrological factors on urban water demand: A multivariate statistical approach. Journal of Hydrology 518: 42-8.

Parandvash, H. and H. Chang. 2016. Analysis of Long-Term Climate Change on per Capita Water Demand in Urban Versus Suburban Areas in the Portland Metropolitan Area, USA. Journal of Hydrology 538: 574-86.

Pérez-Urdiales, M., M. A. García-Valiñas, and R. Martínez-Espiñeira. 2016. Responses to Changes in Domestic Water Tariff Structures: A Latent Class Analysis on Household-Level Data from Granada, Spain. Environmental and Resource Economics 63(1): 167-91.

Polebitski, A., R. N. Palmer, and P. Waddell. 2011. Evaluating Water Demands under Climate Change and Transitions in the Urban Environment. Journal of Water Resources Planning and Management 137(3): 249-57.

Polycarpou, A. and T. Zachariadis. 2013. An Econometric Analysis of Residential Water Demand in Cyprus. Water Resources Management 27: 309-17.

Portland Water Bureau. 2015. Portland metropolitan area household water use for 2011. Last updated March 2015.

Portland Water Bureau. 2016. https://www.portlandoregon.gov/water/29460. Last accessed January 3, 2016.

Praskievicz, S. and H. Chang. 2009. Identifying the Relationships Between Urban Water Consumption and Weather Variables in Seoul, Korea. Physical Geography 30(4): 324-37.

Price, J. I., J. M. Chermak, and J. Felardo. 2014. Low-flow appliances and household water demand: An evaluation of demand-side management policy in Albuquerque, New Mexico. Journal of Environmental Management 133: 37-44.

PRISM Climate Group at Oregon State University. 2015. Monthly precipitation and maximum temperature data for 2011.

Rathnayaka, K., S. Maheepala, B. Nawarathna, B. George, H. Malano, M. Arora, and P. Roberts. 2014. Factors affecting the variability of household water use in Melbourne, Australia. Resources, Conservation, and Recycling 92: 85-94. 
Renwick, M. E. and R. D. Green. 2000. Do Residential Water Demand Side Management Policies Measure Up? An Analysis of Eight California Water Agencies. Journal of Environmental Economics and Management 40: 37-55.

Reynaud, A. 2013. Assessing the impact of price and non-price policies on residential water demand: a case study in Wisconsin. International Journal of Water Resources Development 29(3): 415-33.

Rinaudo, J., N. Neverre, and M. Montginoul. 2012. Simulating the Impact of Pricing Policies on Residential Water Demand: A Southern France Case Study. Water Resources Management 26: 2057-68.

Romano, G., N. Salvati, and A. Guerrini. 2014. Estimating the Determinants of Residential Water Demand in Italy. Water 6: 2929-45.

Ruddell, D. and E. A. Wentz. 2009. Multi-Tasking: Scale in Geography. Geography Compass 3(2): 681-97.

Sebri, M. 2013. Intergovernorate disparities in residential water demand in Tunisia: a discrete/continuous choice approach. Journal of Environmental Planning and Management 56(8): 1192-211.

Shandas, V. and G. H. Parandvash. 2010. Integrating urban form and demographics in water-demand management: an empirical case study of Portland, Oregon.

Environment and Planning B: Planning and Design 37(1): 112-28.

Straus, J., Chang, H., and Hong, C. 2016. An Exploratory Path Analysis of Attitudes, Behaviors and Summer Water Consumption in the Portland Metropolitan Area. Sustainable Cities and Society 23: 68-77.

United Nations Population Fund. 2007. State of the world population 2007: Unleashing the potential of urban growth. New York.

US Census Bureau. 2010. http://quickfacts.census.gov/qfd/states/41/4159000.html. Last accessed February 1, 2016.

US Climate Data. 2017. http://www.usclimatedata.com/climate/portland/oregon/unitedstates/usor0275/2017/1. Last accessed January 4, 2016.

Wheeler-Cook, E., E. Segarra, P. Johnson, J. Johnson, and D. Willis. 2008. Water Conservation Policy Evaluation: The Case of the Southern Ogallala Aquifer. The Texas Journal of Agriculture and Natural Resources 21: 87-100. 
Willis, R. M., R. A. Stewart, D. P. Giurco, M. R. Talebpour, and A. Mousavinejad. 2013. End use water consumption in households: impact of socio-demographic factors and efficient devices. Journal of Cleaner Production 60: 107-15.

Woltemade, C. and K. Fuellhart. 2013. Economic Efficiency of Residential Water Conservation Programs in a Pennsylvania Public Water Utility. The Professional Geographer 65(1): 116-29.

Yasar, A., M. Bilgili, and E. Simsek. 2012. Water demand forecasting based on stepwise multiple nonlinear regression analysis. Arabian Journal for Science and Engineering 37(8): 2333-41.

Yu, X., R. Ghasemizadeh, I. Padilla, J. D. Meeker, J. F. Cordero, and A. Alshawabkeh. 2015. Sociodemographic patterns of household water-use costs in Puerto Rico. Science of the Total Environment 524: 300-9.

Yuan, X., Y. Wei, S. Pan, and J. Jin. 2014. Urban Household Water Demand in Beijing by 2020: An Agent-Based Model. Water Resources Management 28: 2967-80.

Zaied, Y. B. and M. E. Binet. 2015. Modelling seasonality in residential water demand: the case of Tunisia. Applied Economics 47(19): 1983-96. 
Appendix

Process for Transforming Billing Data to Monthly Water Use

Table A1: The table below provides an example of the format of the raw household water use data provided by the Portland Water Bureau.

\begin{tabular}{|c|c|c|c|c|c|c|}
\hline Household & $\begin{array}{l}\text { Metering } \\
\text { Period }\end{array}$ & $\begin{array}{l}\text { Water } \\
\text { Use } \\
\text { (CCF) }\end{array}$ & $\begin{array}{l}\text { Metering } \\
\text { Period }\end{array}$ & $\begin{array}{l}\text { Water } \\
\text { Use } \\
\text { (CCF) }\end{array}$ & $\begin{array}{l}\text { Metering } \\
\text { Period }\end{array}$ & $\begin{array}{l}\text { Water } \\
\text { Use } \\
\text { (CCF) }\end{array}$ \\
\hline A & $\begin{array}{l}2 \text { FEB } 11- \\
1 \text { MAR } 11\end{array}$ & 12 & $\begin{array}{l}2 \text { MAR } 11- \\
31 \text { MAR } 11\end{array}$ & 11 & $\begin{array}{l}1 \text { APR } 11- \\
2 \text { MAY } 11\end{array}$ & 14 \\
\hline B & $\begin{array}{l}31 \text { JAN } 11 \text { - } \\
28 \text { FEB } 11\end{array}$ & 10 & $\begin{array}{l}1 \text { MAR } 11- \\
30 \text { MAR } 11\end{array}$ & 11 & $\begin{array}{l}31 \text { MAR } 11 \text { - } \\
\text { APR } 3011\end{array}$ & 13 \\
\hline $\mathrm{C}$ & $\begin{array}{c}3 \text { JAN } 11-2 \\
\text { APR } 11\end{array}$ & 31 & $\begin{array}{c}3 \text { APR } 11-2 \\
\text { JUL } 11\end{array}$ & 58 & $\begin{array}{l}3 \text { JUL } 11- \\
1 \text { OCT } 11\end{array}$ & 63 \\
\hline
\end{tabular}

Table A2: The table below provides an example of the raw household water use data converted into a daily value (CCF).

\begin{tabular}{|c|c|c|c|c|c|c|}
\hline Household & 27-Feb-11 & 28-Feb-11 & 1-Mar-11 & 2-Mar-11 & 3-Mar-11 & 4-Mar-11 \\
\hline A & 0.4 & 0.4 & 0.4 & 0.3 & 0.3 & 0.3 \\
\hline B & 0.3 & 0.3 & 0.4 & 0.4 & 0.4 & 0.4 \\
\hline C & 0.3 & 0.3 & 0.3 & 0.3 & 0.3 & 0.3 \\
\hline
\end{tabular}

Table A3: The table below provides an example of the daily household water use values aggregated to monthly household water use in CCF.

\begin{tabular}{|c|c|c|c|}
\hline Household & Feb-11 & Mar-11 & Apr-11 \\
\hline A & 11 & 10 & 14 \\
\hline B & 11 & 12 & 13 \\
\hline C & 10 & 12 & 14 \\
\hline
\end{tabular}

